\title{
Debt and De..cit Fluctuations and the Structure of Bond Markets ${ }^{\alpha}$
}

\author{
A lbert Marcet (Universitat Pompeu Fabra, CREI and CEPR) \\ and \\ Andrew Scott (London Business School and CEPR) \\ J une 17-th, 2003
}

\begin{abstract}
A bstract
This paper tests for the market environment within which US ..Scal policy operates, that is we test for the incompleteness of the US government bond market. We document the stochastic properties of US debt and de..cits and then consider the ability of competing optimal tax models to account for this behaviour. We show that when a government pursues an optimal tax policy and issues a full set of contingent claims, the value of debt has the same or less persistence than other variables in the economy and declines in response to higher de..cit shocks. By contrast, if governments only issue one-period risk free bonds (incomplete markets), debt shows more persistence than other variables and it increases in response to expenditure shocks. Maintaining the hypothesis of Ramsey behavior, US data conficts
\end{abstract}

\footnotetext{
״albert.marcet@econ.upf.es, Departament d'E conomia i Empresa, Universitat Pompeu Fabra, Ramon Trias Fargas 25-27, 08005 B arcelona, Spain. ascott@london.edu, Department of Economics, London Business School, Regents Park, London NW 1 4SA, UK. We thank A rantza Gorostiaga, Christel Rendu and, especially, Arpad A braham for research assistance. This work was sponsored by H.M.Treasury and the ESRC's E volving M acroeconomy program. Marcet's research was funded in part by DGES and CIRIT. For comments we thank Fernando Álvarez, Paul K lein, J uan P. Nicolini, V ictor Ríos-R ull as well as seminar participants at CE PR E uropean Summer Symposium in Macroeconomics, Tarragona, CEPR Public F inance Conference, Tilburg, H.M.Treasury, IIES, Stockholm, London School of Economics, Universite de T oulouse, and Universidad T. di Tella. Views expressed in this paper are those of the authors and not necessarily of any sponsoring institution.
} 
strongly with the predictions of complete markets but is much more consistent with incomplete markets. We discuss the implications of this ..nding for the optimality of debt limits, debt management and assessing the sustainability of ..scal policy.

Keywords: Complete vs incomplete markets, Debt M anagement, Government Debt, Optimal ..scal policy, Tax smoothing

J EL classi..cation: E62, H62, H63. 


\section{Introduction}

In this paper we study the evidence that market incompleteness is an important feature determining the behavior of the US ..scal de.cit and the evolution of government debt. We do so by answering the question 'W hat ... nancial market structure justi..es the way that US government debt responds to ..scal shocks?'. M ore precisely, we characterize the response of debt to ..scal shocks under both complete and incomplete markets and compare these with the actual behaviour of US debt. Whether bond markets are complete or incomplete has signi..cant implications for the behaviour of optimal taxes, the imposition of ..scal rules, the assessment of ..scal sustainability and the operation of debt management. Therefore, in order to better design models for policy analysis, it is important to shed some light on this issue.

Whether market incompleteness is an important issue in the data cannot be immediately discovered by casual theorizing or casual empiricism. In many models the Euler equation is identical for complete and incomplete markets so the issue cannot be resolved by testing orthogonality conditions as in GMM estimation. Advocates of incomplete markets might say that due to moral hazard, limited commitment and transaction costs, it is clear that incomplete markets should be introduced into the analysis of models of policy. But this is not enough to rule out complete markets as a reasonable assumption. A recent literature suggests that introducing incomplete markets into asset pricing models does not substantially in $¥$ uence the behavior of real variables and asset prices ${ }^{1}$. In addition a number of authors point out how through the choice of maturity, using ..xed or ¥oating rate debt, price indexed debt or nominal debt or domestic or foreign currency denominated debt, the government has access to a wide range of securities, so it might appear that the complete market model is most appropriate ${ }^{2}$. By providing and implementing a simple test for the existence of market completeness our analysis enables a more de. nitive perspective on this debate.

\footnotetext{
${ }^{1}$ Tellmer (1993), Heaton and Lucas (1996), Krusell and Smith (1998), M arcet and Singleton (1999), among others, make this point by studying simulations of various incomplete markets models.

${ }^{2}$ See, inter alia, B ohn (1990), Calvo and Guidotti (1990), Campbell and Shiller (1996), de Fontenay, Milessi-Feretti and Pill (1995), M issale (1999), Lloyd-Ellis and Zhu (2000) and Chari, Christiano and Kehoe (1991). More recently, Angeletos (2002) and Buera and Nicolini (2003) analyze the case when there are enough maturities to span the set of possible realizations.
} 
Testing for the appropriate structure of government debt markets is not just a matter for theoretical debate but also has important policy implications. Policy discussion is increasingly focused on placing restrictions on government debt e.g. the Stability and Growth Pact in Europe, the Balanced Budget A mendment debate in the US, the Code for Fiscal Stability in the UK. Presumably these constraints are considered in order to prevent governments from shifting a heavy tax burden to future years and to avoid increasing incentives to default or utilizing the infation tax. However, without articulating the constraints faced by actual governments when choosing a debt policy it is impossible to assess the relative merits of alternative ..scal rules. To demonstrate this point, the ..nal section of this paper gives a compelling example of how misleading conventional assessment of ..scal policy sustainability may be when the assumption of complete markets is not valid.

Given the objective of this paper, it is unavoidable to make assumptions about government behavior. The consumption literature reveal ed a long time ago that the budget constraint of a consumer cannot be tested in isolation: additional assumptions are needed to meaningfully test a model, for example, that a consumer is a utility maximizer, resulting in a joint test of utility maximization under a certain budget constraint. For the same reason, we need to model government behavior in testing for the presence of market incompleteness, and any test for whether markets are complete or not must by necessity be of a joint hypothesis of market structure and assumed government behaviour. ${ }^{3}$

Unfortunately there is not widespread agreement regarding the best way to model government behavior. Lucas and Stokey (1983) proposed to study dynamic stochastic models, where the government is assumed to be a benevolent Ramsey social planner who cares about public welfare and takes as given that quantities are determined in equilibrium. In the last ten years there has been a substantial literature characterizing the behavior of tax rates under this assumption (see, inter alia, J udd (1992), Zhu (1992), Chari, Christiano and Kehoe (1994), Klein and Rios-Rull (2000) for complete markets versions and Aiyagari, M arcet, Sargent and Seppälä (2002) and Scott (2003) for incomplete markets). We follow this approach and assume a Ramsey equilibrium. By assuming that the government is a benevolent Ramsey planner we do not intend to invoke this as a precise description of reality (just as utility maximization of expected discounted utility by consumers should not

${ }^{3}$ T his point, in a dixerent way, was argued by Hansen, Roberds and Sargent (1991). 
be taken literally), but given the state of the literature and the sophistication of the models that can be analyzed under this paradigm this seemed to us the best place to start. By following this literature and its associated fully ‡edged dynamic stochastic models of government behavior we can articulate more clearly the point of this paper, which is how the behavior of debt varies under complete or incomplete markets and which hypothesis ..ts the data better. It is in this spirit that we adopt the assumption of a Ramsey planner. ${ }^{4}$

Some studies back up some of the predictions of Ramsey taxes, for example, B arro (1979), Sahasakul (1986), Bizer and Durlauf (1990), J udd (1992), Hess (1993) and Scott (2003). Although some of these studies reveal details concerning the behaviour of debt their main focus is on taxation. Hence one of the contributions of our paper is to provide a comprehensive summary of the behaviour of debt under optimal taxation. Given the greater reliability of government debt statistics compared to estimates of the exective average marginal rate of tax, this recasting of the optimal taxation literature has empirical advantages. Further, because we focus on the behavior rather than the structure of debt we are able to arrive at a remarkably straightforward test for whether government bond markets are complete. This test on the behaviour of debt is much sharper than trying to detect the presence of unit roots in tax rate series (see Scott (2003) for the diф culties in this approach of testing for market incompleteness).

In Section 2 we document the stylized facts about US debt we wish to explain. Focusing on post-war data the main results we show are that debt shows very long lasting swings in response to shocks, far more so than other variables as rełected in a range of persistence measures. Further, VA R analysis shows that the market value of government debt increases in response to positive de. cit shocks. In Section 3 we characterize the behaviour of debt under optimal taxes when the government is able to issue a full range of A rrow contingent securities. We provide a general theorem describing a recursive formulation for debt; we use this formulation to show that under complete markets the market value of debt is no more persistent than real variables in the economy. Further, the market value of debt decreases in response to a persistent increase in government expenditure shocks. Therefore, the im-

\footnotetext{
${ }^{4} \mathrm{~A} n$ alternative would have been to utilise a model from the burgeoning political economy literature. However, there is much less consensus about how to formulate government behavior in this literature in a tractable and fully fedged dynamic stochastic model with incomplete markets.
} 
plications of complete markets are at odds with the established facts in the previous section. In Section 4 we turn our attention to incomplete markets, speci..cally, we assume that the government in our model can only issue one period risk free bonds. Under this assumption, government debt is used as a buxer stock to smooth ¥uctuations. This buxer stock behavior causes debt to be more persistent than other variables in the economy and to increase in response to adverse de..cit shocks. To be more precise we study two alternative models, we derive an analytic result for a particular case, and we resort to simulations to demonstrate the quantitative importance of the exects we derive.

In Section 5 we consider the implications of our ..ndings for the implementation of ..scal policy. Because under incomplete markets government debt shows long and persistent łuctuations we show that it is very diф cult for an observer to discriminate between an unlucky Ramsey planner who has experienced a sequence of adverse shocks and a government which is pursuing an insolvent ..scal policy. This is despite the fact that by construction the government is a Ramsey optimizer and the intertemporal budget constraint is being observed. By contrast, under complete markets discrimination between a Ramsey and an insolvent policy is relatively straightforward. We discuss the implications of this ..nding for the role of debt limits and debt management.

\section{The Behaviour of US Government Debt}

The purpose of this section is to establish some stylized facts about debt in order to evaluate the relevance of our competing theoretical models. Our focus will be on how debt responds to macroeconomic shocks (compared to other endogenous variables) and the serial correlation properties of debt.

The theoretical variable of interest is the market value of outstanding government debt. However, the nearest published equivalent is the face value of outstanding government debt. As detailed in the Data Appendix we use the work and methods of Seater (1981), Cox and Hirschorn (1983) and B utkiewicz (1983) to construct an annual series for the market value covering the period 1900-99. However, in what follows we focus on the post-1950 period, although none of our results are seriously axected by using the longer sample. Our focus on the post-1950 data is to exclude the exects of war - it is well known that inclusion of war time data and resultant structural breaks 
leads to biases in estimates of persistence- so as to focus on business cycle fuctuations. Further, there are sound moral hazard reasons to believe that governments cannot issue war contingent debt so by focusing on the sample 1950-99 we avoid an obvious bias in favor of incomplete markets.

To summarize the properties of the data we consider a minimal VAR which includes the primary de..cit, GDP and the market value of government debt. In order to work with data that is roughly stationary, we use the primary de..cit/GDP ratio, the change in the logarithm of GDP and the debt/GDP ratio. We use the VAR as a convenient way to summarize the data and how debt evolves in response to de..cit and GDP shocks. We do not think of this VAR as a direct way of testing a particular structural model nor as providing a de. nitive characterization of how ..scal policy impacts on the economy ${ }^{5}$. In later sections we estimate exactly the same VAR from data generated by simulations of our theoretical models and in this manner we are able to compare the data and models in a precise way.

Since we are not aiming to identify structural VAR's we take a straightforward approach to orthogonalization and use triangular leading matrices (Cholesky decomposition), and then check that if this particular decomposition brings out the same insights when it is applied to the model. A main focus of our later analysis will be government expenditure shocks and so we order the variables by placing the de.cit ..rst, output growth in second place leaving the debt variable to last so we can detail how debt responds to all other shocks ${ }^{6}$.

Figure 1 shows the estimated impulse response functions from our basic trivariate VAR speci...cation ${ }^{7}$ from which we glean the following Facts:

1. B oth de..cit and GDP shocks have a large and very persistent exect on debt. The exect is more persistent than for all other variables.

2. A higher de..cit today signals a higher de..cit over the next ..ve or six years.

\footnotetext{
${ }^{5}$ See Blanchard and Perotti (1999) or B urnside, Eichenbaum and Fisher (2000) for such an analysis.

${ }^{6}$ We follow the common practice of calling the ..rst orthogonalized shock the 'de..cit shock', the second 'the output shock' and so on. However, we note that this nomenclature may mislead - for instance, in the models we consider the ..rst shock in our estimated VAR contains a large part of the innovation to productivity, since an innovation to output will infuence tax revenues and, therefore, the de..cit.

${ }^{7}$ Results are robust to a wide range of dixerent VAR speci..cations and estimators.
} 
3. the exect of de..cit shocks on debt is positive.

4. the exect of GDP shocks on debt and de..cit is negative.

5. the responses to the debt shock are signi..cantly dixerent from zero for the ..rst few lags of the Debt/GDP equation. The response to this shock is also persistent ${ }^{8}$

Studying impulse response functions provides a highly detailed picture of interactions between endogenous variables but is sensitive to the ordering of variables and the assumed number of shocks. Therefore as an additional more robust (although less informative) measure of persistence we utilize the k-variance ratio de..ned as ${ }^{9}$

$$
P_{y}^{k}=\frac{V a r\left(y_{t} \text { i } y_{t_{i}}\right)}{k \operatorname{Var}\left(y_{t} \text { i } y_{t_{i}}\right)}
$$

In the case of a stationary and ergodic variable we have $\operatorname{Var}\left(y_{t} i \quad y_{t_{i}}\right)$ ! $2 \operatorname{var}\left(y_{t}\right)$ as $k ! 1$. Therefore, for the stationary case $P_{y}^{k} ! 0$ as $k ! 1$. For instance, in the case of an i.i.d. process $P_{y}^{k}=1 \neq k$. By contrast in the case of a pure unit root $P_{y}^{k}=1$ for all $k$. Notice also that $P_{y}^{k}>1$ is consistent with a wide range of stochastic processes, including a unit root with serially correlated growth rates ${ }^{10}$. Hence, the more persistent is variable $y$, the longer it takes for $P_{y}^{k}$ to go to zero as $k$ grows.

\footnotetext{
${ }^{8} \mathrm{~A}$ puzzle in this VAR is what is meant by debt shocks given that the government budget constraint states a non-linear identity between debt, de..cits and interest rates. We have tested if this shock captures interest rate exects, but when we include interest rates in the VAR the size and exect of the debt shock remains essentially unchanged. Three possible explanations can be advanced for this debt shock: i) measurement error - over a long sample there are many changes of de..nition of debt, revaluation exects and asset sales which will axect the identity; ii) approximation error - a linear VA R may not fully capture the non-linear nature of the government's budget constraint and of the Debt/ output ratio; iii) identi..cation problems; it may be that the current identi..cation leaves some de..cit shocks to appear as "debt" shocks.

${ }^{9}$ Cochrane (1988) uses this statistic in the macroeconomics literature to measure persistence in US GDP data.

${ }^{10}$ It can be shown that $P_{y}^{k}=1+{ }_{j=1}^{k P 1} \frac{k_{i} j}{k} 1 / 2$ where $1 / p$ is the correlation of $\phi y_{t}$ with $\$ y_{t_{i}}$. The rising pro..le of $P_{D \text { ebt }}$ shown in Figure 2 is therefore consistent with a wide range of stationary processes for $\$ \mathrm{y}_{\mathrm{t}}$ :
} 
Estimates of $P_{y}^{k}$ for a selection of key variables are shown in Figure 2. Since the $k$ variance ratios for debt are far higher than those for other variables, these con..rm that debt displays substantially more persistence than all other variables and this persistence is marked even after 10 years ${ }^{11}$.

Figures 1 and 2 formalize two features of the data that are hardly surprising: debt is more persistent than other variables and debt moves in the same direction as the primary de. cit.

\section{Debt under Complete $M$ arkets}

Having documented how government debt behaves we now turn our attention to the theoretical part of our paper and begin by studying the behavior of debt under complete markets. We show that, in a very large class of models, equilibrium debt is a time invariant function of the state variables determining the primary de..cit and interest rates. As a consequence, the persistence of government debt will be no greater than any of the variables which determine de..cits and interest rates. Hence, debt under complete markets is no more persistent than other variables, a prediction which is inconsistent with the ..ndings in section 2 (in particular, with Fact 1 from our VAR analysis and the $k_{i}$ variance ratios). We also show that if the primary de..cit process follows an autoregressive process with positive serial correlation, as is the case for the US (Fact 2), then under complete markets debt should decrease in response to an increase in the primary de..cit, so that Fact 3 is inconsistent with complete markets.

\subsection{Recursive Formulation and Persistence of Debt}

Consider the following very general setup

Assumptions on the fundamentals of the model.

The variables in the economy are $f x_{t} ; s_{t} g$; where $s_{t}$ are exogenous shocks and $x_{t}$ endogenous variables. The process $f s_{t} g$ is $M$ arkov and, without loss

\footnotetext{
${ }^{11} \mathrm{~N}$ otice that we do not explore persistence by testing for unit roots. We discriminate between complete and incomplete markets on the basis of the persistence in debt relative to other variables, in terms of the size of impulse responses and k-variance ratios of debt relative to other variables. Hence, we are free from the usual criticism of the low power of unit-root tests.
} 
of generality can be partitioned into two subvectors $s_{t}=\left(s_{t}^{1} ; s_{t}^{2}\right)$ with $s_{t}^{2}$ including those shocks known one period ahead and $s_{t}^{1}$ containing the rest ${ }^{12}$. For simplicity, assume that the distribution of the exogenous shocks conditional on the past has a density. There are I agents and each agent at time $\mathrm{t}$ chooses consumption and obtains net income from several sources. We denote by $!$ consumption good), i.e. expenditure minus income at time $t$.

At time there exists a spot market for claims contingent on all possible values of $s_{t+1}^{1}$ : A bond contingent on a value $s^{1} 2 S^{1}$ will pay one unit of the consumption numéraire if $s_{t+1}^{1}=\bar{s}^{1}$ occurs, and zero otherwise. Here $S^{1}$ ' $\left[{ }_{t=1}^{1}\right.$ f support of $s_{t}^{1} g$ : We denote by $b_{\mathrm{c}}\left(\bar{s}^{1}\right)$ the quantity of bonds contingent on the occurrence of $\bar{s}^{1}$ purchased by agent $i$ at time t. Hence, agent $i$ has to choose a function $b: S^{1} ! R$ in each period, this function may depend on the period and the realization. The payox of this portfolio next period is $b_{c}\left(s_{t+1}^{1}\right)$ and the budget constraint of each agent $i=1 ;:: ;$; satis..es

$$
b_{i_{1}}\left(s_{t}^{1}\right)=!_{t}^{i}+{ }_{s^{1}}^{Z} b_{(}\left(s^{1}\right) p_{t}^{b}\left(s^{1}\right) d s^{1}
$$

for all agents, periods and realizations. Here $p_{t}^{b}\left(s^{1}\right)$ is the price at time t of a bond contingent on $s_{t+1}^{1}=s^{1}$. All agents are prevented from defaulting and from running Ponzi schemes. The term $b_{i_{1}}\left(s_{t}^{1}\right)$ denotes the individual's holdings of a range of Arrow contingent securities. In order to provide a closer link with the data it will also be useful to de..ne the market value of savings as $v b^{\prime} \quad s^{1} b_{i}^{j}\left(s^{1}\right) p_{t}^{p}\left(s^{1}\right) d s^{1}$.

Assumptions on equilibrium.

We assume that in equilibrium de.cits and interest rates can be formulated recursively in the sense that the state variables, $z_{\mathrm{t}}$, the de.cits of all agents, and bond prices are given by time-invariant functions of the state variables; i.e., there exist time-invariant functions $h, f^{i} ; p$ such that

$$
\begin{gathered}
\mathrm{z}_{\mathrm{t}}=\mathrm{h}\left(\mathrm{z}_{\mathrm{t}_{1} 1} ; \mathrm{s}_{\mathrm{t}}\right) \\
! \mathrm{t}_{\mathrm{t}}^{\mathrm{i}}=\mathrm{f}^{\mathrm{i}}\left(\mathrm{z}_{\mathrm{t}_{\mathrm{i}}} ; \mathrm{s}_{\mathrm{t}}\right) \\
\mathrm{p}_{\mathrm{t}}^{\mathrm{b}}\left(\bar{s}^{1}\right)=\mathrm{p}\left(\bar{s}^{1} ; \mathrm{z}_{\mathrm{t}_{1}} ; \mathrm{s}_{\mathrm{t}}\right)^{1}\left(\bar{s}^{1} ; \mathrm{s}_{\mathrm{t}}\right)
\end{gathered}
$$

\footnotetext{
${ }^{12} \mathrm{M}$ ore precisely, $\mathrm{s}_{\mathrm{t}}^{2}$ contains the elements of $\mathrm{s}_{\mathrm{t}}$ that are measurable with respect to $\mathrm{s}_{\mathrm{t}_{\mathrm{i}}}$; and $\mathrm{s}_{\mathrm{t}}^{1}$ those that are not.
} 
for all $\mathrm{i}, \mathrm{t} ; \mathrm{s}^{1} ;$ where $^{1}$ is the density of $\mathrm{s}_{\mathrm{t}+1}^{1}$ conditional on $\left(\mathrm{s}_{\mathrm{t}} ; \mathrm{s}_{\mathrm{t}_{\mathrm{i}}} ; \mathrm{i::}\right)$. We also assume the limiting condition

$$
\lim _{T ! 1} E_{t}^{\tilde{A}} a_{t+T}\left(s_{t+T+1}^{1}\right)_{j=1}^{Y} p\left(s_{t+j+1}^{1} ; z_{t+j i} ; s_{t+j}\right)=0
$$

for all $\mathrm{t}$ and all realizations with probability one.

A large variety of models satisfy these assumptions, including models with multiple agents, public goods, distorting taxation, time-non-separable utility function, externalities, monopolistic power, market frictions, non-rational expectations or credit constraints.

Most models in the literature guarantee that a version of (4) holds as follows: if at least one agent $\bar{i}$ chooses an interior solution for all bonds in all periods, this agent behaves competitively in the bond pnarket, has full information, rational expectations and a utility function $\mathrm{E}_{0}{ }_{\mathrm{t}=0}^{{ }^{-t}} \mathrm{u}^{\overline{\mathrm{I}}}\left(\mathrm{z}_{\mathrm{t}} ; \mathrm{z}_{\mathrm{t}_{\mathrm{i}}} ; \mathrm{S}_{\mathrm{t}}\right)$; then (4) holds with

$$
\mathrm{p}\left(\bar{s}^{1} ; z_{\mathrm{t}_{i}} ; \mathrm{s}_{\mathrm{t}}\right)=-\frac{\mathrm{u}_{\mathrm{c}}^{\mathrm{T}}\left(\mathrm{h}\left(\mathrm{z}_{\mathrm{t}} ; \bar{s}^{1} ; \mathrm{s}_{\mathrm{t}+1}^{2}\right) ; \mathrm{z}_{\mathrm{t}} ; \bar{s}^{1} ; \mathrm{s}_{\mathrm{t}+1}^{2}\right)}{\mathrm{u}_{\mathrm{c}}^{\bar{T}}\left(\mathrm{z}_{\mathrm{t}} ; \mathrm{z}_{\mathrm{t}_{\mathrm{i}}} ; \mathrm{s}_{\mathrm{t}}\right)}
$$

where $u_{c}^{\bar{i}}$ is agent i's marginal utility of consumption. ${ }^{13}$

At this point, we do not know much about the behavior of the bond portfolio $b$ or its market value, vb. These could depend on time, or the realizations of the process, or state variables other than $z$ and $\mathrm{s}$. In particular, the budget constraint (1) may suggest that today's bond portfolio depends directly on debt in the previous period - if this were the case, debt would be likely to display more path dependence and serial correlation than other variables. Key to our analysis is the following result.

Proposition 1 For a model satisfying the above assumptions, given functions $h ; f ; p$

A) the equilibrium portfolio of contingent bonds is given uniquely by a time invariant function $D^{i}$

$$
\dot{b}_{\mathrm{t}}(\phi) D^{i}\left(\phi s_{\mathrm{t}+1}^{2} ; z_{\mathrm{t}}\right)
$$

\footnotetext{
${ }^{13}$ Note that, in this case, ${ }_{j=t}^{Q_{T}} p\left(s_{t+j+1}^{1} ; z_{t+j i} ; s_{t+j}\right)=-T \frac{u_{c}^{\top}\left(z_{t+T} ; z_{t+T} 1 ; S_{t+T}\right)}{u_{c}^{\top}\left(z_{t} ; z_{t_{i} 1} ; s_{t}\right)}$ and (4) is satis..ed as long as the ratio of utilities is guaranteed to be bounded.
} 
for all realizations and all $\mathrm{t}$; $\mathrm{i}$; where

$$
D^{i}\left(s_{t} ; z_{t_{i} 1}\right)^{\prime} !_{t}^{i}+E_{t}{ }_{j=1}^{X} !_{t+j}^{i} \sum_{i=0}^{i 1} p\left(s_{t+i+1}^{1} ; z_{t+i i} ; s_{t+i}\right)
$$

B) The value of the equilibrium portfolio of contingent bonds vbi is given by a (time-invariant) function $V^{i}: Z \notin S^{1} £ S^{2} ! R$ such that

$$
v b_{t}=V^{i}\left(z_{t} ; s_{t}\right){ }^{\prime} E_{t}{ }^{f} D^{i}\left(z_{t} ; s_{t+1}^{1} ; s_{t+1}^{2}\right) p\left(s_{t+1}^{1} ; z_{t} ; s_{t}\right)^{\not \mathfrak{d}}
$$

for all $\mathrm{t}$; i for all realizations.

\section{Proof (See Technical Appendix)}

The ..rst part of this proposition says that the bond portfolio (b) at time $t$ is independent of the realization of $s_{t}^{1}$; furthermore, if $z_{t}$ includes only real variables, as is often the case in models under complete markets, debt is a time-invariant function of only real variables. Past shocks (and time), and the infuence they possibly had on the debt of any agent, bear no in uuence on today's equilibrium value of debt. Instead, under complete markets debt depends in a time invariant manner only on the same variables that allow for the recursive formulation for de..cits and prices. Model 1 below will display an example where this invariance is extreme, in that the government's holdings of A rrow securities never change.

The second part of the proposition ${ }^{14}$ shows that by contrast to the bond portfolio, the market value of debt is in uenced by current shocks. Given the de. nition of vb this can only occur through the impact of shocks on bond prices. More precisely, in the usual case where (6) holds, the impact of today's shock on the marginal rate of substitution and on the conditional density will in uence the market value of debt. But again, in the case when $\mathrm{z}_{\mathrm{t}}$ only contains real variables, and contrary to casual inspection of (1), the inherited value of government debt does not directly axect its market value today.

This result motivates our claim that a model with complete markets and with only real variables in the state vector $z_{t}$ is inconsistent with the high

\footnotetext{
${ }^{14} \mathrm{~T}$ his result is mentioned on $\mathrm{p.625}$ of Chari, Christian and K ehoe (1994) for their model. As the main focus in that paper is to determine the stochastic properties of optimal taxes through simulation, they do not exploit the implications of this result for the behaviour of debt, nor do they report any statistics about the behavior of debt in their simulations.
} 
persistence of debt documented in section 2: part B) of the proposition says that the market value of debt is a function of the same state variables that determine output, therefore debt is unlikely to display more persistence than output under those conditions.

\subsection{Negative Response of Debt to De..cit Shocks}

One other distinctive feature of complete markets to document is how the market value responds to de..cit shocks. For most readers Fact 3 in the previous section would not have been a surprise - debt in the real world is well known to increase when de.cits rise. But it turns out that if the primary de..cit is positively serially correlated (and Fact 2 tells us that it is), the market value of debt under complete markets is likely to fall in response to an increase in the de..cit. Let us build some intuition for this claim.

Consider the standard case when bond prices are given as in (6), then the market value of debt $\left(=i v b^{q}\right)$ is equal to the discounted value of surpluses from next period on e.g

$$
i v b_{t}^{g}=! t_{t}^{g} i \quad b_{t_{1}}^{g}\left(s_{t}^{1}\right)=i E_{t}{ }_{j=1}^{x}-j \frac{u_{c ; t+j}}{u_{c ; t}} !_{t+j}^{g}
$$

where the ..rst equality comes from (1), the second equality from $(19)^{15}$. Consider the (empirically relevant) case that $! \mathrm{g}$ is positively serially correlated. Then, a high de..cit today signals higher than average future $!_{\mathrm{t}+\mathrm{j}}^{\mathrm{g}}$. Then the above expression implies that if a shock that increases the de..cit occurs (say, government spending is high), the right side of equation (9) goes down and so does the value of debt. ${ }^{16}$ To be more precise, consider the special case when

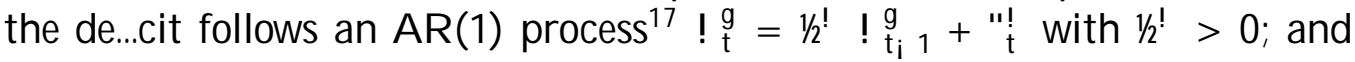

\footnotetext{
${ }^{15}$ T his expression for the value of debt is well known, but we do not know of a reference exploring its implications for the comovement of de..cit and debt.

${ }^{16}$ Our argument pertains to business cycle ¥uctuations of de..cit and debt. One can ..nd examples where government spending and debt increase in the same period under complete markets. O ne case is Example 4 in LS where a high level of $g$ (a "war") occurs with positive probability in some period, but there is no reason why a similarly high level of spending should follow. In that example de..cits are not positively serially correlated and our reasoning does not apply. Our argument holds for non-war periods.

${ }^{17}$ We choose an AR(1) speci..cation here both for reasons of analytical tractability but also because using annual US data 1941-99 on the primary de..cit and standard time series methodology an ARMA $(1,0)$ model was the preferred speci..cation
} 
constant interest rates $\left(u_{c ; t}=1\right)$. Then (9) implies that the market value of debt is equal to $i E_{t} \sum_{j=1}^{l}-j ! \frac{g}{t+j}=i \frac{1 / 2-}{1 i^{1 / 2}-} ! \frac{9}{t}$; and a higher primary de..cit leads to a fall in the market value of government debt $; v^{g}$.

$T$ he reason for this result is the following. Under complete markets agents construct a portfolio that insures them against unanticipated variations in future de..cits. If a high de..cit today signals higher future de..cits, agents construct a portfolio that in the event of a high de..cit covers today's and the higher de..cits that follow. Hence, when the high de..cit occurs, the bond portfolio pays out an amount larger than today's unexpected de..cit, and the agent ..nds himself with higher than average wealth (or lower than average debt); this wealth will be spent when the higher than average de..cits occur in the future.

\subsection{Some Examples}

We now consider some speci..c models in order to illustrate the workings of our proposition and to further back up our claim that facts 1 and 3 are not compatible with complete markets. In the next sub-section we will simulate these models in order to quantify the magnitude of these exects and to explore some results that cannot be obtained analytically.

Model 1 - (No capital accumulation)

This is essentially the model of Lucas and Stokey (1983). We introduce a productivity shock $\mu_{t}$ in order to have output shocks whose VAR can be compared to the one we estimated in section $2 .{ }^{18}$

Output is given by $y_{t}=\mu_{t}\left(1 ; I_{t}\right)$ where $I_{t}$ denotes leisure. The resource constraint is $y_{t}=c_{t}+g_{t}$ where $c$ denotes consumption and g government expenditure. The stochastic process $\mathrm{fg} ; \mathrm{Hg}$ is exogenous and M arkov. A consumer with utility function $\mathrm{E}_{0}{ }_{\mathrm{t}=0}^{-\mathrm{t}} \mathrm{u}\left(\mathrm{c}_{\mathrm{t}} ; I_{\mathrm{t}}\right)$ has access to complete bond markets, behaves competitively, obtains a competitive wage (in equilibrium equal to $\mu_{t}$ ) for each hour worked, and pays labor taxes to the government.

The government levies a proportional tax rate $i t$ on labor income, has access to complete bond markets and faces the budget constraint

$$
b_{t_{1} 1}^{g}\left(g_{t} ; \mu_{t}\right)=g_{t} i_{t} \mu_{t}\left(1 ; l_{t}\right)+{ }^{Z} b_{t}^{g}(g ; \bar{\mu}) p_{t}^{b}(g ; \bar{\mu}) d(\bar{g} ; \bar{\mu})
$$

\footnotetext{
${ }^{18} \mathrm{G}$ orostiaga (1999) also introduces a productivity shock in a similar model.
} 
where $b^{9}$ denote governments bond holdings. The government has a ..xed initial level of bonds and chooses tax rates and government bonds so as to maximize consumer welfare. $B$ oth the consumer and the government observe all shocks up to the current period.

Following Lucas and Stokey, it can be shown that the Ramsey equilibrium satis..es

$$
\left(i_{t} ; G_{t} ; I_{t}\right)=G\left(g_{t} ; \mu_{t}\right):
$$

for all $\mathrm{t}>0$; and a time-invariant function $\mathrm{G}$ :

This economy satis..es all of our assumptions ${ }^{19}$ and using our earlier notation we have the endogenous variables $x_{t}=\left(i_{t} ; c_{t} ; l_{t}\right)$; the exogenous stochastic process $s_{t}^{1}=\left(g_{t} ; \mu_{t}\right)$ and no variables play the role of $s_{t}^{2}$ or $z_{t}$ : The part A) of proposition 1 implies

$$
\mathrm{b}^{g}(g ; \bar{\mu})=D^{g}(g ; \bar{\mu})
$$

for all t $>0$ and all realizations. In other words, the government always buys the same amount of each security in equilibrium, regardless of the current state of the economy and the period. In this model, the debt portfolio does not respond to a shock in government spending or productivity, even though all other equilibrium variables respond to these shocks according to (11). ${ }^{20}$

Part B) of the proposition implies

$$
v b^{g}=V^{g}\left(g_{t} ; \mu_{t}\right)
$$

so that the market value of bonds is inłuenced by current shocks but the inherited value of debt has no direct inłuence on today's value.

Since the market value of debt, output and the de..cit are exact functions of the exogenous shocks, the persistence of debt must be very similar to the persistence of output and de.cit. More precisely, in the case that $g$ and $\mu_{t}$ have the same serial correlation then (up to a linear approximation to the functions $\mathrm{V} g$ and $\mathrm{G}$ ) output, debt and the de..cit all have the same serial correlation as $\left(g ; \mu_{t}\right)$ : This provides a strict proof that, in this case, complete markets is at odds with the higher persistence of debt described in the previous section.

\footnotetext{
${ }^{19}$ Strictly speaking, the recursivity assumptions are only satis. ed in this model for $t>0$. This changes the results in a trivial way: Proposition 1 only holds for $t>0$ :

${ }^{20} \mathrm{~T}$ he portfolio would no longer be constant if we assumed that $\mathrm{fg}_{\mathrm{t}} ; \mu_{\mathrm{t}} \mathrm{g}$ is Markov of order two. More precisely, if the conditional density $f_{g_{t+1} ; \mu_{t+1} j g_{t} ; \mu_{t} ; g_{t_{i}} ; \mu_{t_{i}} ; \ldots . .:}(\phi)=$ ${ }^{1}\left(\phi g_{t} ; \mu_{t} ; g_{i} 1 ; \mu_{t_{i}}\right)$ then, Proposition 1 implies $h_{t}^{g}\left(\phi=D^{g}\left(\phi g_{t} ; \mu_{t}\right)\right.$.
} 
To prove that this model is inconsistent with Fact 3 , consider the case where $\left(g ; \mu_{t}\right)$ follow an $A R(1)$ process. Then, up to a linear approximation, the equilibrium de..cit is AR (1) and, as we argued in the last paragraph subsection 3.2, with constant interest rates debt is equal to $\mathrm{i} \frac{1 / 2}{1_{\mathrm{i}} \frac{1 / 2}{2}}=! \mathrm{g}$. Whether or not the variation in interest rates can compensate the variability of de..cit will be explored by simulation in the next section.

M odel 2 - Capital accumulation under uncertainty

A key focus of our analysis is the relative persistence of debt compared to other variables. Model 1 was a case where debt had the same persistence as output and de..cit. But if a state variable with large persistence is introduced in the model, Proposition $1 \mathrm{~B}$ ) leaves open the possibility that this state variable infuences debt more than output and, therefore, it could be the case that debt is more persistent than output under complete markets. To see whether this is the case in a well-known framework, we introduce capital accumulation. Output is now given by

$$
y_{t}=\mu k_{t i 1}^{\circledast 1}\left(1 ; I_{t}\right)^{1_{i} \circledast}
$$

and the resource constraint becomes

$$
\mathrm{c}_{\mathrm{t}}+\mathrm{k}_{\mathrm{t}} \mathrm{i}\left(1 \mathrm{i} \quad \# \mathrm{k}_{\mathrm{t}_{\mathrm{i}} 1}+\mathrm{g}=\mathrm{y}_{\mathrm{t}}\right.
$$

where \pm is the depreciation rate of capital.

Chari, Christiano and K ehoe (1994) (from now on CCK) show that if the government levies capital and labor taxes, then the model can be formulated recursively with endogenous variables $x_{t}=\left(i_{t}^{1} ; i_{t}^{k} ; l_{t} ; k_{t} ; c_{t}\right)$; exogenous shocks $s_{t}^{1}=\left(g ; \mu_{t}\right)$; endogenous state variable $z_{t}=k_{t}$ and the solution is a timeinvariant function of $\left(g_{i} ; \mu_{i} ; k_{t_{1}}\right)$ for $t>0$. Therefore, part A) of Proposition 1 says that

$$
\log ^{g}(g ; \bar{\mu})=D^{g}\left(g ; \bar{\mu} ; k_{t}\right)
$$

so that the portfolio of debt depends only on today's value of the capital stock. In this case, a shock to the economy has an exect on debt only to the extent that this shock axects capital. If capital has an ergodic distribution and it ‡uctuates around a long run mean, then so does debt.

The market value of debt is given by

$$
v b_{t}^{g}=V^{g}\left(g_{t} ; \mu_{t} ; k_{t}\right):
$$


A gain, past shocks, and the in $¥$ uence they possibly had on government debt, bear no infuence on today's equilibrium value of government debt, over and above the exect that past shocks have on current fundamentals.

This equation expresses our main ..nding in model 2: under complete markets and since only real variables appear in the vector of state variables, the persistence of debt is no greater than the persistence of any real variable in the system. In the previous model we could say without a doubt that if $g$ and $\mu_{t}$ had the same serial correlation then debt, output and de.cit had the same serial correlation, but the inclusion of the highly persistent state variable $k_{t}$ in (13) could infuence dixerently debt and output, so we can not make a similar statement in this model. This can only be resolved by exploring numerical solutions.

\subsection{Simulations}

In this subsection we solve the model numerically both to see if the failure of the CM model is quantitatively important and to study some issues that could not be addressed analytically.

We assume the utility function

$$
u\left(c_{t} ; I_{t}\right)=\frac{c_{t}^{I_{i}{ }^{\circ}}}{1 i^{\circ}{ }_{1}}+B \frac{l_{t}^{1_{i}{ }^{\circ}{ }_{2}}}{1 i^{\circ}{ }_{2}}
$$

and set ${ }^{-}=0.98$ and ${ }^{\circ}=1,{ }_{2}=2$. We set $B$ so that the share of leisure in the time endowment equal to $30 \%$ on average.

In keeping with the literature, we assume $g$ follows a truncated $A R(1)$, and $\mu_{t} a \log A R(1)$ process

$$
\begin{aligned}
& 8 \\
& <9 \\
& g_{t}=: \frac{g}{(1} \\
& (1 ; 1 / 2) g^{\alpha}+1 / 2 g_{i}+{ }_{t} g \\
& \text { if }(1 ; 1 / 2) g^{\alpha}+1 / 2 g_{i_{1}}+{ }_{t} g / g \\
& \text { if }\left(1 ; \frac{1}{2}\right) g^{d \alpha}+1 / 2 g_{i_{1}}+{ }_{t}^{11 g}<\underline{g} \\
& \text { otherwise } \\
& \log \mu_{t}=1 / 2 \log \mu_{t_{1}}+\mu_{t}
\end{aligned}
$$

for "g. " $t \mu$ i.i.d., mean zero and mutually independent. To facilitate comparisons across examples, we assume both shocks have the same persistence, i.e. $1 / 2=1 / 2$ : We assume " $\mu \gg N\left(0 ; 0: 007^{2}\right) ;{ }^{\prime g} \gg N\left(0 ; 1: 44^{2}\right) ; g^{a}=17: 5$; with an upper bound of $\mathrm{g}$ is $35 \%$ and $\mathrm{g}=15 \%$ of average GDP. These values are chosen so that in the non-stochastic steady state of Model 1, government 
expenditure amounts to 25 percent of GDP and ‡uctuates within the range 15 and $35 \%$ of output. We consider two dixerent assumptions regarding the persistence of the shocks: a) both sequences are i.i.d. $(1 / 2=1 / 2=0)$ and, b) strongly positively serially correlated shocks $1 / 2=1 / 2=0: 95^{21}$. For Model 2 we set $1 / 2=1 / 2=0: 95, \AA=0: 4$ and the depreciation rate $\pm=0: 05:$ For the impulse response functions we used a debt limit that is never binding in equilibrium and has the roly only of ruling out Ponzi schemes.

The focus of our analysis is how debt behaves under complete and incomplete markets and introducing capital taxation causes problems for this issue. CCK show that if the government has access to a full set of ex post contingent capital taxes, these can be used to complete the markets. Our analysis in the rest of the paper is therefore predicated on the assumption that contingent capital taxes are unavailable to the government, and in both models we only allow for labor taxes. ${ }^{22}$.

We use both impulse-response functions (IRF) and the k-variance ratio to measure persistence. In using IRF's we start by studying the response of each variable to the fundamental shocks in the model economy $\left(g_{t} ; \mu_{t}\right)$ : We call this the "true IRF". We obtain the $i_{i}$ th coec cient of the true IRF by computing numerically how each variable would change i periods ahead if, starting from the steady state mean, the innovation to each shock had a realization equal to $(3 / 4 ; 0 ; 0 ;::), j=g ; \mu$ When the true IRF coec cients at low frequencies are large relative to the coec cients at high frequencies we will say that the variable has high persistence. In order to ensure consistency with Section 2 we also compute the IRF by estimating an identical VAR (a Cholesky decomposition on the de..cit ratio, GDP growth and debt ratio) using simulated data to that we estimated in Section 2 on US data. We call

\footnotetext{
${ }^{21}$ All models are solved using the Parameterised Expectations A lgorithm described in den Haan and Marcet (1990). To solve the incomplete markets models we use the approach in A iyagari, M arcet, Sargent and Seppälä (2002). To solve the models with capital accumulation we use the adaptations described in Abraham, M arcet and Scott (2001).

${ }^{22} \mathrm{CCK}$ show simulation results where $\ddagger$ uctuations in the ex post capital tax rate are allowed to complete the market in the absence of state contingent debt. The volatility required in capital taxes is extreme - a standard deviation of around 40 compared to a mean of 0 (see Table 2 in CCK ). E ven accepting the argument in J udd (1992) that conventional measures of capital taxes understate volatility by ignoring corporate allowances it is hard to observe this volatility in the data. For this reason we interpret our simulation results as showing that complete markets, whether produced by contingent bonds or contingent capital taxes, cannot account for the empirical ..ndings of Section 2. These issues are further explored in Abraham, Marcet and Scott (2001).
} 
this the "estimated IRF". The true IRF helps us understand the properties of our model, while the estimated IRF enable us to compare directly the model with the data.

The dashed lines of Figures 3 to 5 show the true IRF's of a number of endogenous variables under complete markets, and Figure 6 shows the kvariance ratio for various models under both complete and incomplete markets. Figure 3 shows Model 1 under i.i.d. shocks ${ }^{23}$. Not surprisingly, under complete markets, given the i.i.d. nature of the shocks and equations (11) and (12), all variables including debt are i.i.d., and all variables have zero persistence, including debt. The ..rst panel in the ..rst column of Figure 6 shows the k-variance ratio for the same variables and shows an identical degree of persistence across them all.

Figure 4 shows the true IRFs from the same model but now assuming persistent shocks $1 / 2=1 / 2=0: 95$. As expected from (11) and (12), under complete markets the persistence in the shocks is passed through all the endogenous variables and the response of each variable is now much more distinctive. In all cases the response declines roughly geometrically, at a rate of decay approximately equal to $1 / 2$. The middle panel of the left column in Figure 6 shows that all variables have approximately equal persistence.

Since we have now a serially correlated de.cit we can explore if the model explains Fact 3. Figure 4 shows that debt goes down (up) in response to a higher $g_{t}\left(\mu_{t}\right)$ : The response of the primary de..cit to each shock is now the opposite from that shown by debt. This con..rms the results in subsection 3.2 that persistent shocks which increase the de..cit cause debt to decrease under CM, making this model incompatible with Fact 3.

The dashed lines in Figure 5 show the true IRF s from introducing capital accumulation as in Model 2 with complete markets. Each panel tells interesting stories about the response of each variable, but here we will concentrate on the persistence of debt and the response of debt to de..cit shocks. Note that most of the true IRFs decay to zero from an initially high level, the main exception being the response of output to government spending, which shows a relatively large long run negative exect after an initially positive response. Also notice that the responses to the productivity shock are longer-lived. None of the responses are humped-shaped, and certainly not the response of debt, suggesting that persistence is about the same in all variables. If anything, the persistence of output could be largest, given its

\footnotetext{
${ }^{23}$ T he vertical axis in Figures 3 to 5 are in units of the variable under consideration.
} 
response to government spending. Notice that once more the de..cit and the debt respond in opposite ways to each shock, in contradiction to Fact 3.

The ..nal panel of F igure 6 con..rms that according to the k-variance ratio output is more persistent than debt under CM. Recall that we introduced model 2 to have a better chance to match the higher persistence of debt with complete markets, but the result of introducing capital is to take the model even further away from the data: output is now more persistent than debt!.

To ..nally see if all these responses mix in a way that looks like the estimated VAR from US data e.g Figure 1, we explore estimated IRF only for model 2. Figure 7 shows that the estimated IRF are signi..cantly dixerent from those estimated using US data, most signi..cantly we see that the re sponse of debt does not show high persistence and that Fact 3 is strongly rejected.

To summarize the results in this section: the complete market analysis is inconsistent with our ..ndings for US data, particularly Facts 1 and 3. In the data, de..cit and GDP are axected by ..scal or GDP shocks but the impact dies out quite quickly; however, the impact on debt is much more persistent and takes a very long time (if ever) to fade away, the opposite to what complete markets imply. Further, the response of debt to adverse de. cit shocks under $\mathrm{CM}$ is the opposite to that observed in the data. These results suggest that governments use variations in the market value of debt as a buxer stock for ..scal shocks rather than using the insurance role that bond interest payments play in the case of complete markets.

\section{Debt under Incomplete M arkets}

In this section we show that incomplete markets perform much better in accounting for the data. Because market incompleteness covers a wide range of possibilities we cannot show a completely general result. However, by using a variety of examples combined with intuition we suggest that under incomplete markets the persistence of government debt is greater than that in other variables in a large variety of models, and that the response of debt to a de..cit shock is of the observed sign. The reason for this behavior is that under incomplete markets debt is used as a buxer stock to smooth fuctuations, and as a result a shock today in $¥$ uences the stock of debt for a long time. 


\subsection{An Intuition}

Under complete markets if the government experiences, for example, unexpectedly low revenue or high spending, it would have previously insured against this kind of shock via issuing contingent debt, and the payox from the portfolio would help oxset the shock and the higher than average future shocks. But under incomplete markets it is the size of debt that helps to partly insulate tax rates from these shocks. Consider a government that enforces a balanced budget in each period. Such a policy would cause taxes to be very volatile and, under standard assumptions on preferences, leads to a loss of welfare. A better policy (if contingent debt is not available) is to use government debt as a buxer stock: by increasing debt in bad periods and decreasing it in good times the government could achieve smoother taxes. The problem with ...nancing the de..cit in this manner is that the higher debt will, via the intertemporal budget constraint, generate higher interest payments in the future and so higher future tax rates. Optimal ..scal policy involves using debt as a buxer stock to reduce volatility of tax rates in the very short run, and shifting this volatility to the very far future, much in the way that precautionary savings are used in the consumption literature. The exect is to produce long and persistent swings in debt.

This exect of debt on future taxes under incomplete markets is at the heart of the unit-root/ persistence properties of taxes and debt that we outline in this section. As shown in Barro (1979) and Aiyagari, Marcet, Sargent and Seppälä (2002) (henceforth A M SS) an increase in government spending has a permanent exect on taxes (in the sense that taxes are a risk-adjusted martingale) precisely because under incomplete markets the government uses debt to buxer the impact of shocks on tax rates. As a consequence, under incomplete markets debt displays substantial persistence compared to other variables as well as a positive response to de..cit shocks.

\subsection{An Example}

We consider a special case of M odel 1 that we can solve analytically. This will help to understand that under incomplete markets debt has higher persistence. The only shock to the de. cit will occur in period $t=1$. The evolution of all variables after this period can be interpreted as the response to the shock in period 1. We will see that under incomplete markets the de..cit responds strongly in period 1 and weakly thereafter, while the response of 
debt is permanent. This is very dixerent from what would occur under a similar probabilistic structure in a standard growth model, where capital stock would converge to its steady state value so that the exect of this one-time shock would die out as time passed.

A ssume, in Model 1 , that $g$ is only random for $t=1$. In particular $P\left(g_{1}=g^{H}\right)=P\left(g_{1}=g^{L}\right)=: 5$ and $g^{H}=g+^{\prime} ; g^{L}=g i{ }^{\prime} ;$ for some ; $g>0$. Government spending is constant in all other periods: $g_{0}=g=g$ for all t, 2: Assume that $\mathrm{u}(\mathrm{c} ; \mathrm{I})=\mathrm{c}+\mathrm{H}(\mathrm{I})$ and that initial debt is zero: $\mathrm{b}_{1}^{\mathrm{g}}=0$ :

The only ..nancial asset in the economy is a risk-less one-period bond and the government levies only labor taxes. Therefore, the budget constraint of the government is

$$
g+p_{t}^{b} b_{t}^{g}=w_{t} i_{t}\left(1 ; l_{t}\right)+b_{t i 1}^{g}
$$

and the de..cit is ! ${ }_{t}^{g}{ }^{\prime} w_{t} i_{t}\left(1_{i} I_{t}\right)$ :

Denote with superscripts $H$ and $L$ the values of all variables under each realization of $g_{1}$. The following result states how a government reacts to this shock under complete or incomplete markets.

\section{Result 1}

Under regularity assumptions (stated in the Technical A ppendix)

2 Under complete markets

the only period where the de..cit is in $¥$ uenced by the shock is $t=1$ :

$$
\begin{aligned}
& ! \frac{g}{0}=! \frac{g}{2}=! \frac{g}{3}=:::=0 \quad \text { for all realizations } \\
& !{ }_{0}^{\mathrm{g}}<! \frac{\mathrm{g}}{1} \mathrm{H}>! \frac{\mathrm{g}}{2}
\end{aligned}
$$

Furthermore, debt does not respond to a de..cit shock: ${ }^{24}$

$$
\mathrm{i} \mathrm{vb}_{\mathrm{g}}^{\mathrm{g}}=0 \text { for all } \mathrm{t}=0 ; 1 ; \ldots: \text { and all realizations }
$$

2 Under incomplete markets

\footnotetext{
${ }^{24} \mathrm{~T}$ his example does not display the negative correlation of debt and de..cit under CM which we have discussed in subsection 3.2. This is not surprising since in the present example de..cit is not positively serially correlated.
} 
the de..cit has an immediate positive response to a high $\mathrm{g}^{\mathrm{l}}$; and future de..cits display a permanent negative response:

$$
!_{0}^{\mathrm{g}}<!_{1}^{\mathrm{g} ; \mathrm{H}}>!_{2}^{\mathrm{g} ; \mathrm{H}}=!_{3}^{\mathrm{g} ; \mathrm{H}}=::: \text { and } !_{0}^{\mathrm{g}}>!_{2}^{\mathrm{g} ; \mathrm{H}}
$$

Furthermore, debt has a positive and permanent response to a high de..cit:

$$
\mathrm{i} v b_{0}<\mathrm{i} v b_{1}^{H}=\mathrm{i} v b_{2}^{H}=:::
$$

All inequalities reversed (and equalities still hold) in the event $g_{1}=g^{L}$ :

See proof in the Technical Appendix.

Therefore in this stylized example debt shows a permanent response to a ..scal shock under incomplete markets: if government spending is high (low) in period 1, debt increases (decreases) and it remains at this higher (lower) level forever. Even if the shock dies out after one period, its exect on the de.cit is much larger in the period when the shock occurs than in the future, and debt stays at the same level implied by the shock forever, thus displaying a persistence greater than any other variable.

\subsection{Simulations}

To con..rm our intuition in the case of fully $¥$ edged dynamic stochastic models we turn once again to M odels 1 and 2 and study simulations under incomplete markets. There are many ways in which bond markets can be incomplete but we consider the polar case where the government can only issue one period risk free bonds. This is obviously an extreme example for, as was discussed in the introduction, in reality governments have access to a range of dixerent types of bonds with varying maturities. This is important for, as shown in Angeletos (2001) and Buera and Nicolini (2003), it is possible to achieve the complete markets outcome so long as there exist as many maturities as potential realizations of shocks and the yield curve shows suc cient ‡exibility to oxer insurance across most states of nature $e^{25}$. Therefore the value of the debt portfolio in these papers is the same as the value of debt under the A rrow securities we considered in section 3 . Hence, our ..ndings in section 3 would say that data on US debt cannot be matched by the models of Angeletos (2001) and Buera and Nicolini (2003).

\footnotetext{
${ }^{25}$ See $\mathrm{M}$ arcet and Scott (2001) for an investigation as to which combination of bond issuance performs best in this respect for OECD governments.
} 
The only change that incomplete markets requires to our M odels 1 and 2 of section 3 is that the budget constraint of the government is now (14). In addition, we introduce now a debt limit for the government bo limit, in addition to ruling out Ponzi schemes, will now allow us to explore the exect of debt limits that are binding in equilibrium. For the simulations we set $\underline{B}$ equal to $80 \%$ of average GDP. This is a loose debt limit that does not drive the results in most periods. See section 5 for the behavior of the model under tighter debt limits.

The results are shown in the dotted lines of Figures 3 to 5 and the right column of Figure 6 . In the i.i.d. case of Figure 3 the initial response of debt is muted compared to other variables but it continues to accumulate so that it eventually becomes the most axected variable. The response of debt to productivity shocks is also shifted to long lags, indicating that productivity shocks have a highly persistent exect on debt. The k-variance ratio in Figure 6 (top right panel) con..rms that the market value of debt contains more persistence than any of the other variables. Notice also that the responses of the de..cit and debt to each shock in the ..rst few periods have the same sign. The response of de..cit in the longer run changes sign, due to the fact that a higher debt interest will have to be serviced in the future in response to an increase in debt today.

When shocks are persistent, the dotted lines in Figure 4 reveal a more complex picture. The immediate response of debt to the adverse expenditure shock is again small compared to other variables but once more it accumulates so that the exect of the shock is shifted to low frequencies. The same pro..le appears in response to the persistent productivity shocks, although here the accumulation of debt takes a lot longer. Unlike the case of complete markets, the response of debt to both shocks is hump-shaped and eventually declines at a slow rate. The combination of the humped response and the slower rate of decline of the true IRF cause the k-variance ratios to reveal substantially more persistence of debt in the case of incomplete markets - compare the middle panels of Figure 6: debt is not only more persistent than any other variable under incomplete markets but more than ten times as persistent as under complete markets. If anything, the model overshoots, since now the k-variance ratios for debt reach a value of about 4 after 10 years, while in the data they only reached a value of 2 after 10 years

Furthermore, Figure 4 also shows that incomplete markets reverses the response of debt to government expenditure and productivity shocks. Now debt responds in the same way as the de..cit in the short run so that Fact 3 
can be explained by incomplete markets. We also note that under incomplete markets, de..cits in the distant future have to decrease in order to prevent debt from exploding as in the estimated IRF for the data.

Figure 5 con..rms all of these results for our model with capital accumulation. It is interesting to note that both output and debt have a roughly equally persistent response to an innovation in $\mathrm{g}$, while the response of debt to an innovation in $\mu$ is much more persistent than the response of output to the same shock. Debt seems to display the greatest persistence amongst the endogenous variables since it shows clearly humped shaped IRF, and it increases in response to shocks that cause the primary de..cit to grow. This is con..rmed in Figure 6, where debt displays the higher ratios.

A gain, the dotted line in the lower panels of Figure 5 shows that under incomplete markets debt responds in the same direction as de..cit at most lags. A gain, in the long run the IRF of de..cit has to reverse sign in order to pay for the additional interest.

Model 2 also improves the ..t of the k-variance ratios. In particular, comparing the corresponding panels of Figure 6 we see that the ..rst three k-variance ratios are almost equal to one, and that the ratios for debt grow over the computed lags, just as in the data. In any case, the persistence is still too high in Model 2, since the debt k-variance ratios reach a value of about 6 at 10 years lag as compared with 2 in the data. This suggests that the nature of incomplete markets that we have assumed - the government only being able to issue one period risk free bonds - is too extreme compared with the options governments actually face. However, it is also apparent that even though the government may possess some options for partly mitigating market incompleteness they do not seem able to exploit these fully enough to make complete markets the most rel evant environment for examining optimal ..scal policy - introducing market incompleteness improves dramatically the ..t of the model with US data. ${ }^{26}$

We show the estimated IRF from Model 2 in Figure 8. This con..rms that, in model 2, debt is more persistent than any other variable under incomplete markets, and that debt goes up in response to a higher de..cit when the de..cit shock is identi..ed as in the data VAR. Although this model falls short of matching all aspects from the data VAR (facts 4 and 5 are still

\footnotetext{
${ }^{26}$ We have checked that this sort of behavior of debt under incomplete markets is present under most parameter values and under various models that we have explored. For example, the same sort of behavior occurs in the model of Gorostiaga (1999), which introduces frictions in the labor market and endogenous government spending.
} 
unaccounted for within the framework of this paper), it is clear that under capital accumulation incomplete markets does much better than complete markets. Including capital accumulation improves the ..t of the model with the data and it makes the case in favor of incomplete markets even stronger. ${ }^{27}$

\section{Sustainability, Debt Limits and Debt M an- agement}

A large literature has discussed the desirability of imposing limits on government debt and ways to test for ..scal sustainability, both from an academic and a policy-oriented point of view. It is worthwhile reconsidering this issue in the light of the above results.

We will show that under incomplete markets it is very diф cult to distinguish between optimizing and irresponsible governments. In this environment, the virtue of debt limits is that they are an exective way to ensure sustainability of ..scal policy, and they can be monitored with very little information. On the other hand, debt limits constrain the choices of government and as a result will be very costly under some circumstances. We argue that improvements in debt management are desirable not only because it provides better insurance against shocks to the primary de..cit but also because it enables debt limits to target unsustainable policies more exectively and because it makes it easier to distinguish irresponsible from optimizing governments.

\subsection{Sustainability}

We argue that the large swings in government debt that are a feature of incomplete markets cause problems for exorts to assess sustainability. A large literature has developed tests of sustainability of ..scal policy. ${ }^{28}$ Many

\footnotetext{
${ }^{27}$ Our extreme assumption that rates of return are risk free may also be responsible for producing excessive persistence. Sleet (2002), motivated by the results of this paper, investigates the case where governments have access to private information so that rates of return oxer limited state contigency but markets are still incomplete. Whilst debt is still persistent it is less so than when debt is completely risk free.

${ }^{28}$ See inter alia, Flavin and Hamilton (1986), Trehan and Walsh (1991), and Bohn (1998). Hansen, R oberds and Sargent (1991) discuss diф culties in testing sustainability if observations on debt are not available.
} 
of these tests have been criticized because of their low power in a statistical sense $e^{29}$; we will argue they have little power in that a monitoring agency processing information optimally would ...nd it diф cult to distinguish the optimal (and sustainable) ..scal policy from an unsustainable policy.

Consider a monitoring agency that, given $T$ observations on the debt/ GDP ratio, has to assess whether a government is pursuing a sustainable ..scal policy when, in fact, the data are generated by Model 1 with persistent shocks. The agency does not know the true model, and assumes that the debt/ output ratio (' $\left.D_{t}=Y_{t}\right)$ follows an $A R(n)$ process. The agency is likely to choose the simplest AR(1) model

$$
\frac{D_{t}}{Y_{t}}=\circledR+b \frac{D_{t_{i} 1}}{Y_{t_{i} 1}}+e
$$

since this would ..t the data very well (in fact, the $\mathrm{R}^{2}$ coed cient in this regression with model-generated data is always very close to one). We say the ..scal policy is unsustainable if $b>1$ : If $0<b<1$ we say ..scal policy is sustainable and we say debt is strongly mean-reverting if bis not close to 1 .

A ssume that the agency processes data optimally given the AR (1) model. The best summary of the available information is given by Bayesian posterior probabilities for $\mathrm{b}$ We say that the agency perceives that ..scal policy is likely to be unsustainable after $\mathrm{T}$ periods if it ..nds

$$
\operatorname{Post}_{T}(b, 1)>\operatorname{Post}_{T}(b<1)
$$

where $\mathrm{P}$ ost $\mathrm{T}_{\mathrm{T}}$ are the posterior probabilities with a sample of $\mathrm{T}$ observations. If (18) holds, the agency would conclude that ..scal policy is more likely to be unsustainable than otherwise; this would be a wrong conclusion since in our simulations the policy is, by construction, sustainable. The question we want to study is: what is the probability that (18) holds?. Under standard assumptions and assuming the agency has no prior beliefs on $b$, the B ayesian posterior is normally distributed with mean equal to the OLS estimator (boLS). Therefore, (18) holds if and only if boLS, 1, so that the probability that the monitoring agency achieves the wrong conclusion is Prob(bols, 1):

\footnotetext{
${ }^{29}$ For example, Bohn (1998) argues that the lack of power of unit root tests plagues most sustainability tests. The test proposed by Bohn, allows for strong increases in debt in the face of large increases in government spending, so it would not detect unsustainable policies that did not repay debt incurred in the face of large de..cits.
} 
Figure 9 shows the M onte-Carlo distribution of bots under complete and incomplete markets from 500 simulations. The data are simulations of M odel 1 with persistent shocks and where $T=40$. Under complete markets we have $E\left(b_{T}^{\mathrm{QLS}}\right)=0.814$, but under incomplete markets $\mathrm{E}\left(\mathrm{b}_{\mathrm{O}}^{\mathrm{OLS}}\right)=0.988$. Hence, under incomplete markets, the optimal policy is on average perceived to be borderline unsustainable. More striking is the fact that in only $0.6 \%$ of cases did bols exceed 1 under complete markets, compared to $48 \%$ under incomplete markets. These are the probabilities that (18) holds.

In other words, since government policy is sustainable in M odel 1 (in fact, it is optimal within all sustainable ..scal policies) the agency would almost never reach the wrong conclusion as in (18) under complete markets, but under incomplete markets it would reach the wrong conclusion almost half of the times. The monitoring agency might just as well forget about posterior probabilities and decide if ..scal policy is sustainable by tossing a coin!. The reason for this substantial error is that the large and sustained swings in the debt/ output ratio that are optimal under incomplete markets and persistent shocks will often be mistaken as explosive and unsustainable path for debt unless allowance is made for the incompleteness of bond markets. A nother way to say this is that the debt/ output ratio is weakly (strongly) mean reverting under incomplete (complete) markets. So under complete markets a test of mean reversion is likely to give a correct answer, not so under incomplete markets.

\subsection{Debt Limits}

The fact that it is so dic cult to test for sustainability under incomplete markets can be used to make a case for imposing debt limits as a way to ensure sustainability. Debt limits are costly, but if they help to ensure sustainability, it may be worthwhile imposing them. We now turn to consider the cost of debt limits for an optimizing government.

To investigate the extent to which debt limits inłuence optimal debt and taxes, we simulated Model 1 under three dixerent assumptions about debt limits: tight debt limits which bind at $10 \%$ of steady state GDP, moderate limits of $40 \%$ of steady state GDP and ..nally loose constraints of $105 \%$ of steady state GDP. The results are shown in Table 1. Under the assumption of i.i.d. shocks and complete markets the variations in the market value of debt are minimal (a result consistent with Proposition 1). Under incomplete 
markets debt ‡uctuations are more noticeable but constraints rarely bind. ${ }^{30}$ In the case of persistent shocks, even under complete markets the model generates substantial variation in the debt/GDP ratio. As the range of variation from the loose debt limits show, in the face of incomplete markets the debt/GDP ratio needs to show enormous variation.

$\checkmark$ iewed from the perspective of these simulations the problem with debt limits is clear: they fail to discriminate between governments which have been unlucky and require large variations in debt to pursue an optimal (incomplete markets) ..scal policy and governments who are pursuing insolvent policies which also produce a large increase in debt. Debt limits ensure sustainability at the cost of further constraining those governments that are experiencing bad times. Unless debt management helps insulate tax rates from adverse shocks then an optimizing government will often experience a binding debt limit in bad periods.

\subsection{Debt management and Fiscal Policy}

Our analysis provides a clear role for debt management - to buy/ issue securities which oxer a negative covariance between interest payments and the primary de..cit and so reduce ₹uctuations in debt and tax rates. The better debt management is, the more appropriate the complete market model is in explaining the data. Getting closer to complete markets is important for two reasons: it helps reduce the volatility of taxes in a direct way, and it makes sustainability easy to test by requiring debt to have a strong reversion to the mean (a low bin equation (17)), therefore eliminating the need for harsh measures such as debt limits to ensure sustainability.

Table 2 shows some details from our simulations of Models 1 and 2. As to be expected in all the complete market models the negative correlation between interest payments and the primary de..cit is larger than under incomplete markets and as a consequence tax rates show very little volatility. As emphasized in Scott (2003) tax rates change only because of variations in the elasticity of labor supply and not because of shocks to the government's intertemporal budget constraint. B ecause the elasticity of labor supply changes very little there is little variation in taxes under complete markets. But when

\footnotetext{
${ }^{30}$ Notice the asymmetry in the behaviour of debt - the minimum values are always greater in absolute value than the peaks. This is a similar ..nding to Chari, $\mathrm{K}$ ehoe and M cGrattan (1994) who ..nd that because of precautionary motives governments try and accumulate assets to avoid hitting the upper bound on debt limits.
} 
governments issue only risk free debt, interest payments can no longer ensure the intertemporal budget constraint holds: debt goes up in response to a higher de..cit, and taxes have to increase in the distant future in order to pay for the higher interest payments. Hence, taxes need to be more variable and, in particular, they need to have a large low-frequency variability, as found in our k-variance ratios of the previous section. In Model 1 with persistent shocks taxes are ten times more volatile in the incomplete market model, whereas in Model 2 they are 17 times more volatile. It is interesting to note that the negative correlation between interest payments and the primary de.cit is larger for the case of persistent shocks than for i.i.d. shocks. Because in our model we assume the government can only issue one-period risk-free debt, interest payments are unable to adjust to these i.i.d. shocks. However, when shocks are persistent future interest rates are also axected and this provides some insurance to the government.

A nother interesting feature of our simulations is how under complete markets the primary de..cit is more volatile compared to the incomplete markets case. Under complete markets taxes respond less to government expenditure shocks so that shocks feed through mostly into the primary de.cit. However, swings in the primary de..cit are oxset by fuctuations in interest payments to produce very limited ¥uctuations in the total de..cit. By contrast, under incomplete markets taxes shift in the same direction as government expenditure shocks reducing the volatility of the primary de..cit. Therefore incomplete markets lead to a more muted automatic ..scal stabilizer.

\section{Conclusion}

We have characterized the optimal behaviour of government debt under both complete and incomplete ..nancial markets. W hen markets are complete government debt shows the same or less persistence than other variables in the economy; furthermore, debt falls in response to a higher de..cit. US data is inconsistent with both of these implications of complete markets: debt is more persistent than de.cit and output, and debt goes up with a higher de..cit. Both puzzles are solved by the introduction of incomplete markets. This observation allows us to test complete versus incomplete markets and to conclude that the latter ..ts better the data. Testing complete versus incomplete markets is not straightforward but concentrating on the implications for debt has provided a clear-cut test. 
A s stressed in the introduction we have had to make an assumption about government behavior, and we have used the maintained hypothesis of Ramsey behavior. This leaves open the possibility that the data can be explained by complete markets and non-Ramsey taxation. Examining alternative models for taxation is beyond the scope of this project, even if a tractable and widely accepted alternative existed (which it does not). However, the logic of Section 4 is likely to extend to a wide category of assumptions on government behavior. The observed higher persistence of debt, and the fact that debt and de..cit go up together, will be present whenever debt is used as a buxer stock to smooth out de. .cit ‡uctuations. A s long as a government cares about reducing the impact of shocks on the economy, it will use the payox of the debt portfolio to smooth de..cit shocks under complete markets, but it will have to resort to the use of debt as a buxer stock to smooth de..cit shocks under incomplete markets. This is why we think our results are likely to go well beyond the two Models we use and Ramsey taxation in general.

We have modelled incomplete markets by assuming that only a one-period real riskless bond is available to the government. ${ }^{31}$ Certainly, most governments have access to policy instruments that allow them to construct richer debt portfolios (varying maturity, indexed or conventional debt, etc). If these instruments were thought to exectively complete markets in the real world then they would suxer from the same two puzzles of complete markets we have outlined (lack of persistence in debt and perverse response of debt to de..cit shocks). The fact that the complete market model has diф culty accounting for the observed behaviour of debt is perhaps not surprising when one considers three commonly suggested mechanisms for achieving market completeness: state contingent capital taxation, state contingent infation and issuing full maturity of bonds. In order to achieve market completeness through these mechanisms some extreme behaviour needs to be assumed. Exceedingly high volatility of inłation or capital taxes would be needed in order to complete markets with these instruments ${ }^{32}$. Furthermore, the conjecture by Angeletos, Buera and Nicolini that issuing a wide variety of dixerent

\footnotetext{
${ }^{31}$ It is beyond the scope of this paper to endogeneize the reason for market incompleteness. This is a promising avenue of research. Sleet (2002), building on the results of our paper, provides a private information explanation for the behavior of government debt.

${ }^{32}$ CCK (1991) report in Table 3 that the standard deviation of infation with uncontingent debt is either $20 \%$ or $60 \%$ depending on the degree of risk aversion. CCK (1994) report in Table 2, that the standard deviation of capital taxes with uncontingent debt is $41 \%$ or $30 \%$, again depending on risk aversion.
} 
maturity bonds can complete the market can only be achieved with extreme portfolio holdings of dixerent maturities. ${ }^{33}$ Since we do ..nd that, in a certain sense, our assumption on market incompleteness (only one period risk free bonds) is too extreme (we refer here to the fact that the k-variance ratio for debt is too high even for Model 2, see subsection 4.3) studying models where these instruments have a role in providing better insurance is a promising avenue for research. But enough rigidities would be needed so that these instruments are not able to go all the way and exectively complete markets, and to allow that the buxer stock behavior of debt plays a suc ciently important role. ${ }^{34}$

Our ..nding of the importance of incomplete markets suggests two other directions for research. Our result shows that there are signi..cant shocks to the ..scal de..cit which are not hedged by current US debt management. Discovering these shocks and how to hedgeagainst them (if possible) promises to reduce łuctuations in the level of US debt and volatility in tax rates. In addition, given the presence of incomplete markets our results suggest that a crude approach to debt limits as a sign of ine\$ cient ..scal management may be misleading and that a more detailed examination of sustainability is required. Finally, while our focus has been entirely on the government sector, much of the analysis is of a greater generality and its application to discover the importance of market incompleteness faced by other agents in the economy, such as household, corporate or even the nation, is worth pursuing.

\footnotetext{
${ }^{33}$ Buera and Nicolini (2003) calibrate an example where the government has to go very long or very short on various maturities, by as much as 500 or $600 \%$ GDP, in order to complete markets.

${ }^{34}$ Schmitt-G rohe and U ribe (2002) study a model with incomplete markets and in $\ddagger$ ation policy where infation can not complete the markets due to sticky prices.
} 


\section{R eferences}

[1] A braham, A., Marcet, A . and Scott, A. (2001) "Optimal tax policy in dynamic economies with incomplete markets ", London B usiness School mimeo.

[2] A iyagari, R .,M arcet, A., Sargent, T.J . and Seppälä, J . (2002) "O ptimal Taxation without State-Contingent Debt", J ournal of Political Economy, 110, 1220-1254

[3] Angeletos, G-M (2001) "Fiscal policy with non-contingent debt and optimal maturity structure", forthcoming Quarterly J ournal of E conomics

[4] Barro, R.J . (1979) "On the determination of the public debt", J ournal of Political Economy, 87, 940-71.

[5] Bizer, D and Durlauf, S (1990) "Testing a positive theory of government ..nance", J ournal of Monetary E conomics, 26, 123-41

[6] Blanchard, O. and Perotti, R. (1999) "A n empirical characterization of the dynamic exects of changes in government spending and taxation on output", NBER Working Paper 7269.

[7] B ohn, H. (1990) "Tax Smoothing with ..nancial instruments ", A merican Economic Review, 80(5) 1217-30.

[8] B ohn, H. (1998) "T he B ehavior of Public Debt and De..cits", Quarterly J ournal of Economics, Vol. CXIII, pp 949-964.

[9] Buera F. and J .P. Nicolini (2003) "Optimal Maturity of Government Debt with Incomplete Markets", J ournal of Monetary E conomics forthcoming.

[10] Butkiewicz, J .L (1983) "T he Market Value of Outstanding Government Debt : A Comment", J ournal of Monetary E conomics, 11, 373-379

[11] Burnside, C., Eichenbaum, M. and Fisher, J . (2000) "Assessing the effects of ..scal shocks", NBER Working Paper 7459.

[12] Calvo, G. and Guidotti, P.E. (1990) "Optimal maturity of nominal government debt : An In..nite Horizon model", International Economic Review 33, 4, 895-919. 
[13] Campbell, J.Y and Shiller, R.J (1996) "A scorecard for indexed government debt" NBER Macroeconomics A nnual (eds) B. Bernanke and J. Rotemberg

[14] Chari, V.V , Christiano, L.J and Kehoe, P.J (1991) "Optimal Fiscal and M onetary Policy : Some Recent Results", J ournal of Money, Credit and Banking 23: 519-40

[15] Chari, V.V., Christiano, L.J . and Kehoe, P.J . (1994) "Optimal Fiscal Policy in a Business Cycle Model", J ournal of Political Economy, 102, 617-652.

[16] Cochrane, J . (1988) "How big is the random walk in GNP? ", J ournal of Political Economy 96, 893-920.

[17] Cox, W .Michael and Hirschorn, E (1983) "T he market value of US government debt, M onthly, 1942-80" J ournal of Monetary Economics 11, 261-272

[18] de Fontenay, P., Milessi-Ferretti and H. Pill (1995) "T he role of foreign currency debt in public debt management ", IMF Working Paper 95/2.

[19] den Haan, W. and Marcet, A. (1990) "Solving the stochastic growth model by parameterizing expectations", J ournal of Business and Economic Statistics, 8, 31-34.

[20] Flavin, M.A. and Hamilton, J.D. (1986) "On the limitations of government borrowing : A Framework for Empirical testing ", American Economic Review 76, 4, 808-19.

[21] Gorostiaga, A. (1999) "Should Fiscal Policy be Dixerent in a NonCompetitive Framework?", working paper, CEM FI, Madrid.

[22] Hansen, L., Roberds, W. and Sargent, T.J . (1991) "Time series implications of budget balance and of martingale models of consumption and taxes ", in L.P. Hansen and T.J . Sargent Rational Expectations Econometrics Westview Press Inc.

[23] Heaton, J and Lucas, D (1996) "Evaluating the exects of incomplete markets on risk sharing and asset pricing ", J ournal of P olitical E conomy 104, 443-487. 
[24] Hess, G (1993) 'A test of the theory of optimal taxes for the United States 1869-1989', Review of Economics and Statistics, 75,712-716

[25] J udd, K (1992) "Optimal Taxation in Dynamic Stochastic Economies: Theory and Evidence", Stanford University mimeo

[26] Klein, P. and J.V. Ríos-Rull (2000) "Time-Consistent Fiscal Policy", working paper, University of Pennsylvania.

[27] Krusell, P. and A. Smith (1998) "Income and Wealth Heterogeneity in the Macroeconomy", J ournal of Political Economy, 106:5, 867-896

[28] Lloyd-Ellis, H. and Zhu, X. (2000) "Fiscal Shocks and Fiscal Risk Management ", Université du Quebec Working Paper No.108.

[29] Lucas, R.E. and Stokey, N.L. (1983) "O ptimal Fiscal and M onetary Policy in an Economy without Capital", J ournal of Monetary Economics, $12,55-93$.

[30] Marcet, A. and K.J. Singleton (1999) "Equilibrium Asset Pricing and Saving under Incomplete Markets and Portfolio Constraints", Macroeconomic Dynamics, 3, pp 243-277

[31] Marcet, A. and Scott, A. (2000) "Fiscal Insurance and OECD Debt Management ", London Business School mimeo.

[32] Missale, A . (1999) Public Debt M anagement, Oxford : Oxford University Press.

[33] Sahasakul, C (1986) 'T he US evidence on optimal taxes over time', J ournal of Monetary Economics, 251-75

[34] Seater, J (1981) "T he market value of outstanding govrnment debt 1919$75 "$, J ournal of Monetary E conomics 8, 85-101

[35] Schmitt-Grohé, S. and M. Uribe (2002) "Optimal Fiscal and M onetary Policy under Sticky Prices", mimeo, University of Pennsylvania.

[36] Scott, A. (2003) "Does tax smoothing imply smooth taxes?", London Business School mimeo. 
[37] Sleet, C (2002) "Optimal Taxation with Private Government Information", University of Iowa mimeo

[38] Trehan, B. and Walsh, C. (1991) "Testing intertemporal budget constraints : Theory and applications to US Federal Budget and Current A ccount de..cits " J ournal of Money, Credit and Banking 23(2), 206-23.

[39] Tellmer, C. (1993) "A sset Pricing puzzles and incomplete markets", J ournal of Finance 48, 1803-32.

[40] Zhu, X. (1992) "Optimal Fiscal Policy in a Stochastic Growth Model", J ournal of E conomic Theory, 58, 250-289. 


\section{Data Appendix}

We use annual US data. Data for the total de..cit, government expenditure and tax revenue from 1900 to 1999 was from the Economic Report of the President and downloaded from www.ibert.org/ de..cit.html. The BEA website provided current and constant price GDP (available from 1900 and 1929 respectively). Interest payments were available on a ..scal year basis from 1940 onwards at http:// w3.access.gpo.gov/ usbudget. These were converted into a calendar year basis by multiplying adjoining years by 0.25 and 0.75 e.g. 1941 interest payments were calculated as 0.75 of 1940/ 41 ..scal year payments plus 0.25 of $1941 / 42$..scal payments. The resulting series was then removed from the total de..cit series to arrive at a primary de..cit series from 1940 onwards.

The main complication was in ..nding a consistent series for the market value of US government debt. Seater (1981) provides an annual series for 1919 to 1975. Cox and Hirschorn (1983) provide a monthly series between 1945 and 1980. As the latter shows these two studies arrive at highly consistent results. Butkiewicz (1983) outlines a more time ed cient way of calculating the series and again reveals discrepancies to be small between the alternative approaches. We therefore construct a market value series from 1919 to 1999 using a) Seater for 1919 to 1975 b) Cox and Hirschorn 1976-1980 and c) extend the series to 1999 using B utkiewicz formula and OECD data, Central Government Debt Statistics. The full data is available upon request.

A lthough we have been careful to do our study with the market value of debt, which is the appropriate counterpart of debt in the model, the results in section 2 stay almost the same for a measure of the total outstanding debt from $O E C D$. 


\section{Technical A ppendix}

\section{Proof of Proposition 1}

First of all, since $S_{t}$ is Markov and given (2), (3), (4), the conditional expectations involving future de.cits conditional on the past are a function only of $\left(\mathrm{s}_{\mathrm{t}} ; \mathrm{z}_{\mathrm{t}_{\mathrm{i}}}\right)$; therefore $\mathrm{D}^{\mathrm{i}}$ satisfying (8) is time-invariant.

To show part A) notice that

$$
\begin{aligned}
\dot{b}_{i 1}\left(s_{t}^{1}\right) & =!_{t}^{i}+{ }_{s^{1}}^{Z} \dot{d}_{(}\left(s^{1}\right) p\left(s^{1} ; z_{t_{i} 1} ; s_{t}\right)^{1}\left(s^{1} ; s_{t}\right) d s^{1} \\
& =!_{t}^{i}+E_{t} i_{d}^{d}\left(s_{t+1}^{1}\right) p\left(s_{t+1}^{1} ; z_{t_{1} 1} ; s_{t}\right)^{\Phi} \\
= & !_{t}^{i}+E_{t}{ }_{j=1}^{N} !_{t+j}^{i} p\left(s_{t+i+1}^{1} ; z_{t+i i} ; s_{t+i}\right)
\end{aligned}
$$

for all $t$; i. The ..rst equality uses (1) and (4), the second equality uses the de. nition of conditional expectation, and the third equality is obtained by recursive forward substitution of the random variable $b_{t}\left(s_{t+1}^{1}\right)$ and (5).

To show that $D^{i}\left(\phi S_{t+1}^{2} ; z_{t}\right)$ is an equilibrium portfolio it is enough to show that this portfolio satis..es the budget constraint (1) for all $t ; i$ and all realizations, and for the equilibrium prices (4). Note that

$$
\begin{aligned}
& D^{i}\left(s_{t}^{1} ; s_{t}^{2} ; z_{t_{i} 1}\right)=!{ }_{t}^{i}+
\end{aligned}
$$

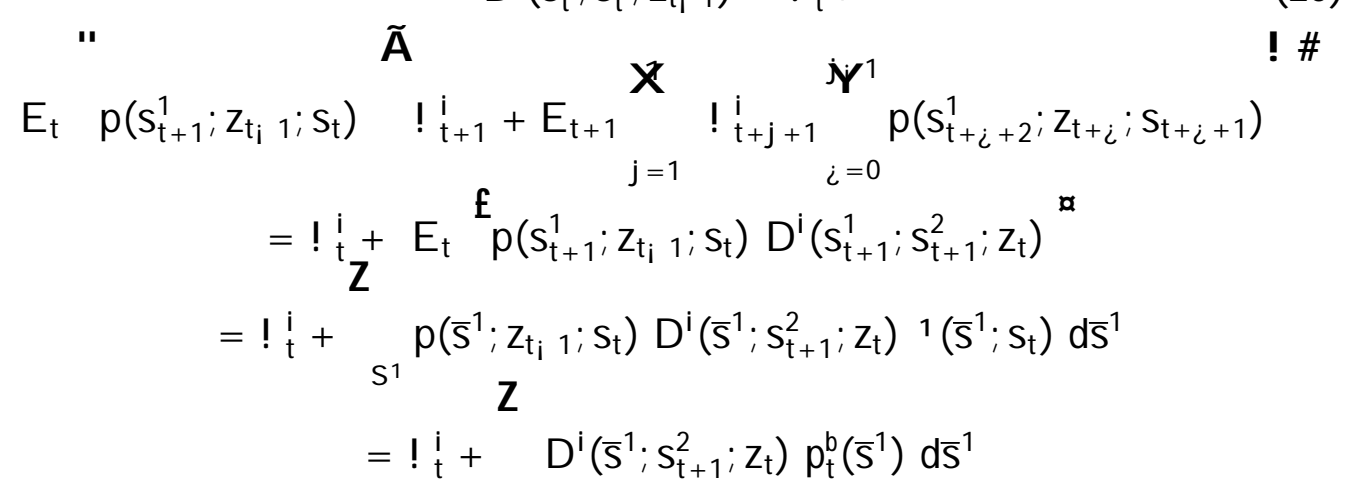

Here, the ..rst equality follows from the de. nition of $D^{i}$ and the law of iterated expectations, the second equality again from the de..nition of $D^{i}$, the third equality from the de..nition of conditional expectation and the fact that $s_{t}^{2}$ 
is known one period in advance, and the last equality from the formula for equilibrium bond prices.

Therefore, taking $b_{d}\left(\phi=D^{i}\left(\phi s_{t+1}^{2} ; z_{t}\right)\right.$, the budget constraint of all agents is satis..ed, so that this gives the equilibrium portfolio.

To establish part B) note that the Markov and recursivity assumptions imply that $V^{i}$ is time invariant. Proposition 1 and (4) imply

Z

$s_{s^{1}} b_{d}^{d}\left(s^{1}\right) p^{b}\left(s^{1}\right) d s^{1}=s_{s^{1}} D^{i}\left(s^{1} ; s_{t+1}^{2} ; z_{t}\right) p\left(s^{1} ; z_{t} ; s_{t}\right){ }^{1}\left(\bar{s}^{1} ; s_{t}\right) d s^{1}=V^{i}\left(z_{t} ; s_{t}\right)$ $¥$

A ssumptions and Proof of Result 1 in Subsection 4.2.

The ..rst order conditions of the consumer and of the Ramsey optimizer under both complete and incomplete markets imply 35

$$
\begin{gathered}
H^{q}\left(I_{t}\right)=1 ; i_{t} \\
H^{q}\left(I_{t}\right)+, t\left[1 ; H^{q}\left(I_{t}\right)+H^{q}\left(I_{t}\right)\left(1 ; I_{t}\right)\right]=0
\end{gathered}
$$

where, $t$ is the Lagrange multiplier of the government budget constraint.

We now state some assumptions on $\mathrm{H}$. Denote by $\propto$ ( $\phi$ the function mapping feasible revenue values into the corresponding multiplier, guaranteeing that (22) is satis..ed; Formally, for any feasible $\bar{R}$, is de..ned as

$$
x(\bar{R})^{\prime}, i \frac{1 ; H^{q(\bar{I})}+H^{q}(\bar{I})(1 ; \bar{I})}{H^{q}(\bar{I})}
$$

where $\bar{I}$ is the corresponding labor satisfying $\bar{R}^{\prime}\left(1 ; H^{q}(\bar{I})\right)(1 ; \bar{I})$.

We assume $\mathrm{H}$ is such that $\alpha$ is monotone $e_{-}^{36}$. We also need to assume

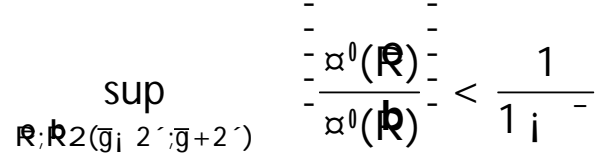

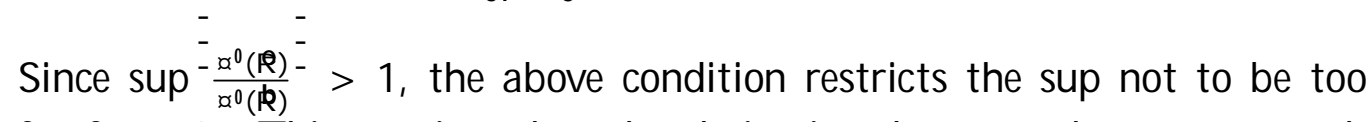
far from 1. This requires that the derivative does not change too much

${ }^{35}$ See, for example, AMSS.

${ }^{36} \mathrm{Su}$ ç cient conditions on $\mathrm{H}$ for this result are found in footnote 14 in AMSS. 
in the relevant range for revenues or, in words that " $\alpha$ is suc ciently linear around $\mathrm{g}^{\prime \prime}$. In particular, if $\mathrm{H}$ is linear-quadratic as in many of the examples of Lucas and Stokey (83) this condition is trivially satis..ed. Another suф cient condition-is that ${ }^{\infty}$ is suф ciently small in the sense that

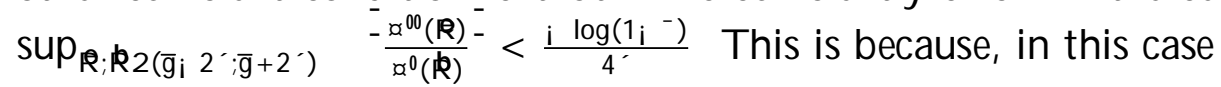

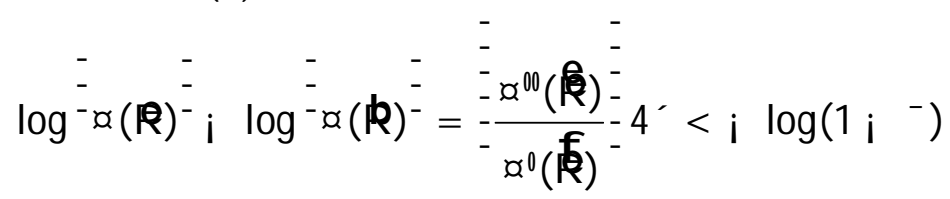

In the usual case that ${ }^{-}$is close to 1 this is not a very restrictive assumption.

We assume that there is an interior solution with probability one in all periods for both the consumer and the government.

Proof

For the government spending process above we have

$$
E_{t}\left(g_{t+j}\right)=g \text { for all } t, 0 \text { and for all } j>0:
$$

Following Lucas and Stokey (1983), under complete markets (22) is satis..ed with,$t=$, for all $t$. This, together with (21) implies that leisure and taxes are constant, say $\mathrm{I}^{\mathrm{cm}}=\mathrm{I}_{\mathrm{t}} ; i^{\mathrm{cm}}=i \mathrm{t}$.

From the budget constraint of the government at period zero we have

$$
0=E_{0}^{X}-t !_{t}^{g}={ }_{t=0}^{X}-t\left(E_{0}(g) i i^{c m}\left(1 ;\left.\right|^{c m}\right)\right)=\frac{9 i i^{c m}\left(1 ;\left.\right|^{c m}\right)}{1 i^{-}}
$$

where the ..rst equality uses $u_{c}^{0}=1$; the second equality uses constancy of taxes and leisure, and the third equality uses (24). Therefore,

$$
\begin{aligned}
& !_{\mathrm{t}}^{\mathrm{g}}=g \mathrm{i} i^{\mathrm{cm}}\left(1 ;\left.\right|^{\mathrm{cm}}\right)=9 \mathrm{i} i^{\mathrm{cm}}\left(1 ;\left.\right|^{\mathrm{cm}}\right)=0 \quad \mathrm{t}=0 ; 2 ; 3 ; \cdots: \\
& !_{\mathrm{t}}^{\mathrm{g} ; \mathrm{H}}=\mathrm{g}^{\mathrm{H}} \mathrm{i} i^{\mathrm{cm}}\left(1 ; \mathrm{I}^{\mathrm{cm}}\right)=\mathrm{g}^{\mathrm{H}} ; \mathrm{g}={ }^{\prime}>!_{0}^{\mathrm{g}} \quad \mathrm{t}=1
\end{aligned}
$$

This proves the statements about the de..cit under complete markets.

The value of debt satis..es

$$
i v b_{t}^{g}=i{ }_{j=1}^{X}-j\left(E_{t}\left(g_{t+j}\right) i i^{c m}\left(1 ; \quad l^{c m}\right)\right)=0
$$


for all t; where the ..rst equality follows from (9) and constancy of taxes and hours, and the second equality follows from (24) and our analysis of de..cit. This shows our statements about debt under complete markets.

Under incomplete markets, following AMSS we have that the ..rst order conditions of the planner are (21), (22), the budget constraint and

$$
, t=E_{t}(, t+1)
$$

for all t. Since there is no uncertainty after period 1, (25) implies that $E_{t}(, t+1)=, t+1$ for all $t, 1$, so that,$t=, 1$ for all $t, 1$ : Then (22) implies $\mathrm{I}_{1}=\mathrm{I}_{\mathrm{t}}$ and $(21) i_{1}=i_{\mathrm{t}}$ for all $\mathrm{t}, 1$ and all realizations, and since $\mathrm{g}$ is also constant after period 2 we have $! \frac{g}{2}=! \frac{g}{t}$ for all $t>2$ and all realizations, proving the equalities of (15).

From proposition 1 in AMSS, and since in this example $p_{t}^{b}={ }^{-}$, we have

$$
b_{t_{1}}^{g}=E_{t}{ }_{j=0}^{X}-j !_{t+j}^{g} \quad \text { for all } t:
$$

This and the fact that de..cit is constant for t, 2 imply

$$
i v q^{g}=i^{-} b^{g}=i^{-} \frac{g i i_{1}\left(1 ; l_{1}\right)}{1 i} \quad \text { for all } t, 1
$$

which proves the equalities in (16).

The remainder of this proof shows that $!_{1}^{\mathrm{g} ; \mathrm{H}}>!_{0}^{\mathrm{g}}$ : Since (26) and the equalities in (15) imply that $b_{1}^{g}=\frac{\bar{g}_{i} i_{1}\left(l_{i} l_{1}\right)}{l_{i}}$, and by assumption $b_{1}^{g}=0$, the budget constraint of the government at periods 0 and 1 imply

$$
{ }^{-}{ }^{1}\left(\Sigma_{0}\left(1 ; I_{0}\right) ; \quad g\right)=b^{g}=g_{1} i i_{1}\left(1 ; I_{1}\right)+\frac{-9 i i_{1}\left(1 ; I_{1}\right)}{1 ;}
$$

Let us denote revenue by $R_{t}{ }^{\prime} i_{t}\left(1 ; I_{t}\right)$. Since the last equation holds for both realizations of $g_{1}$ and $\mathrm{lg}_{\mathrm{g}}$ is not random, we have

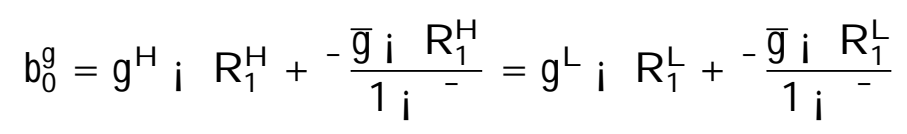

and, since $g^{H}$ i $g^{L}=2^{\prime}$ this implies

$$
R_{1}^{H} \text { i } R_{1}^{L}=\left(1 i^{-}\right) 2^{\prime}>0:
$$


Given the process for $\mathrm{g},(25)$ at $\mathrm{t}=0$ implies

$$
\propto\left(R_{0}\right)=\frac{\not\left(R_{1}^{H}\right)+\not\left(R_{1}^{L}\right)}{2}
$$

thus, since $R_{1}^{H}>R_{1}^{L}$ and $x$ is monotone we have

$$
R_{1}^{H}, R_{0}, R_{1}^{L}
$$

A ssume towards a contradiction that $\mathrm{R}_{1}^{\mathrm{H}}<\mathrm{g}$ : Then equation (28) would imply that $\mathrm{bg}_{\mathrm{g}}>0$ and (31) that $\mathrm{R}_{0}<\mathrm{g}$ : Together with the ..rst equality in (27) we have that $\mathrm{bo}_{\mathrm{g}}<0$, which is a contradiction. Therefore, $\mathrm{R}_{1}^{\mathrm{H}}>\mathrm{g}$. Similarly, we could prove $R_{1}^{L}<g$ and, together with (29), these inequalities imply

$$
\mathrm{R}_{1}^{\mathrm{H}} ; \mathrm{R}_{1}^{\mathrm{L}} 2\left(\mathrm{~g} \text { i } 2^{\prime} ; \mathrm{g}+2^{\prime}\right)
$$

Now:

$$
\begin{aligned}
& \left.\left(R_{1}^{H} i R_{0}\right) \propto \bar{R}\right)=\propto\left(R_{1}^{H}\right) ; \not\left(R_{0}\right)= \\
& \frac{\not\left(R_{1}^{H}\right) ; \not\left(R_{1}^{L}\right)}{2}=\frac{\not^{0} \bar{R}\left(R_{1}^{H} i R_{1}^{L}\right)}{2}=x^{3} \bar{R}\left(1_{i}{ }^{-}\right)^{\prime}
\end{aligned}
$$

where the ..rst and third equalities follow from the mean-value theorem for some $\bar{R} ; \overline{\mathrm{R}} 2\left(\mathrm{R}_{1}^{\mathrm{L}} ; \mathrm{R}_{1}^{\mathrm{H}}\right)$; the second equality from (30) and the last equality from (29). This equation implies the ..rst inequality in

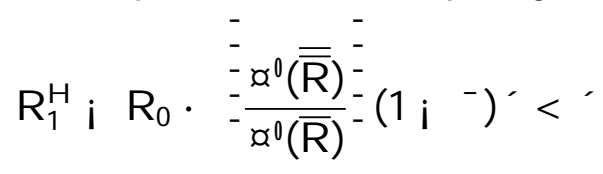

and the last inequality follows because (32) implies $\overline{\overline{\mathrm{R}}} \mathbf{i} \overline{\overline{\mathrm{R}}}^{\overline{-}}$. $4^{\prime}$ and from the bound in equation (23)

Thus we have $\mathrm{R}_{1}^{\mathrm{H}} \mathrm{i} \mathrm{R}_{0}<{ }^{\prime}$ and since $\mathrm{g}_{1}^{\mathrm{H}} \mathrm{i} \mathrm{g}_{0}={ }^{\prime}$, we have that ${ }_{1}^{\mathrm{g}} \mathrm{H}>$ ! ${ }_{0}^{\mathrm{g}}$ :

All the remaining inequalities stated about incomplete markets follow from this fact and analogous arguments. $\#$ 
Pesponse to Cholesky One S.D. Imouations \pm 2 S.E
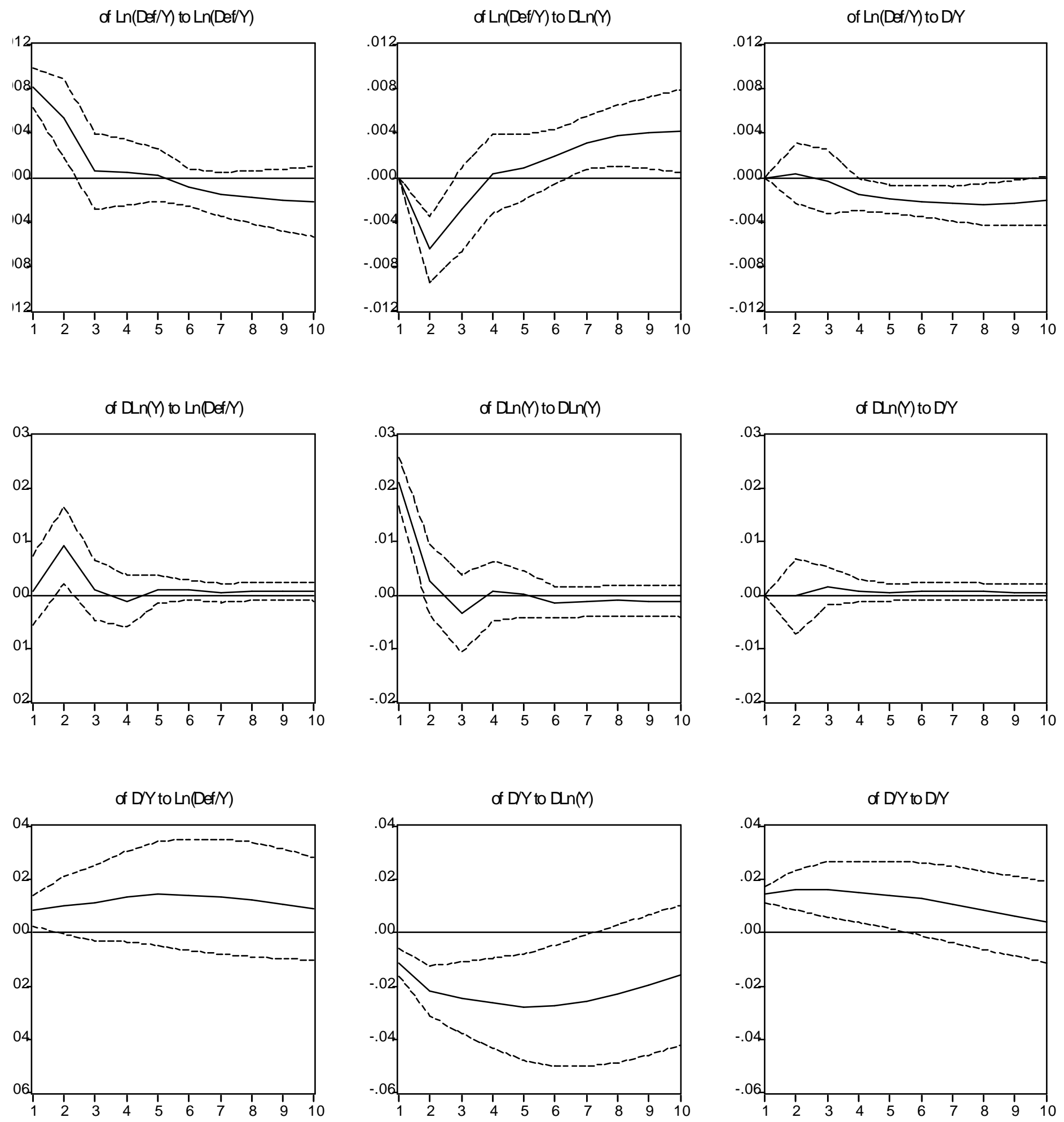

Figure 1

Estimated Impulse Response Functions on US Data 1950-99. 


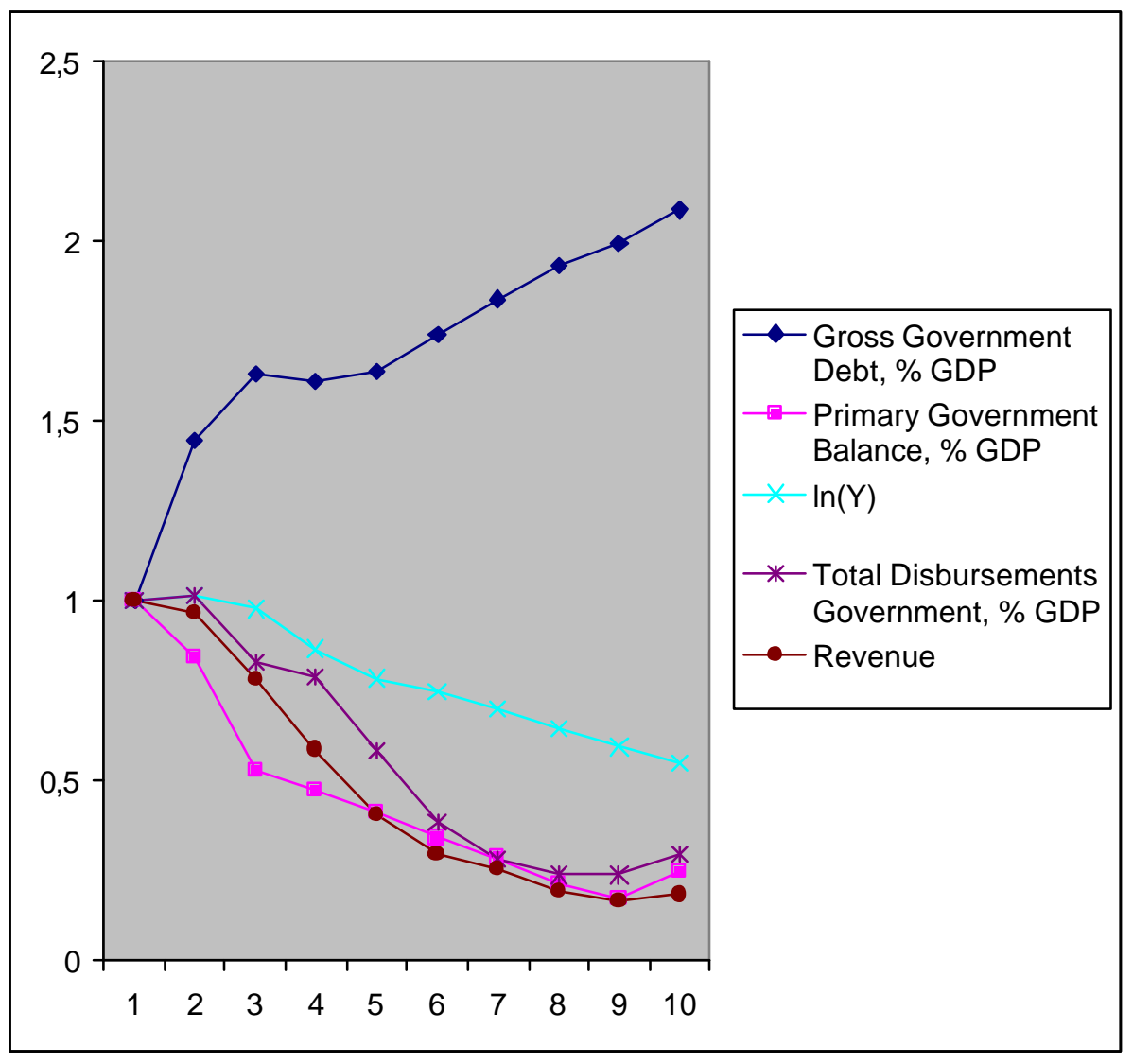

Figure 2

k-variance statistic for US data. 1950-99 

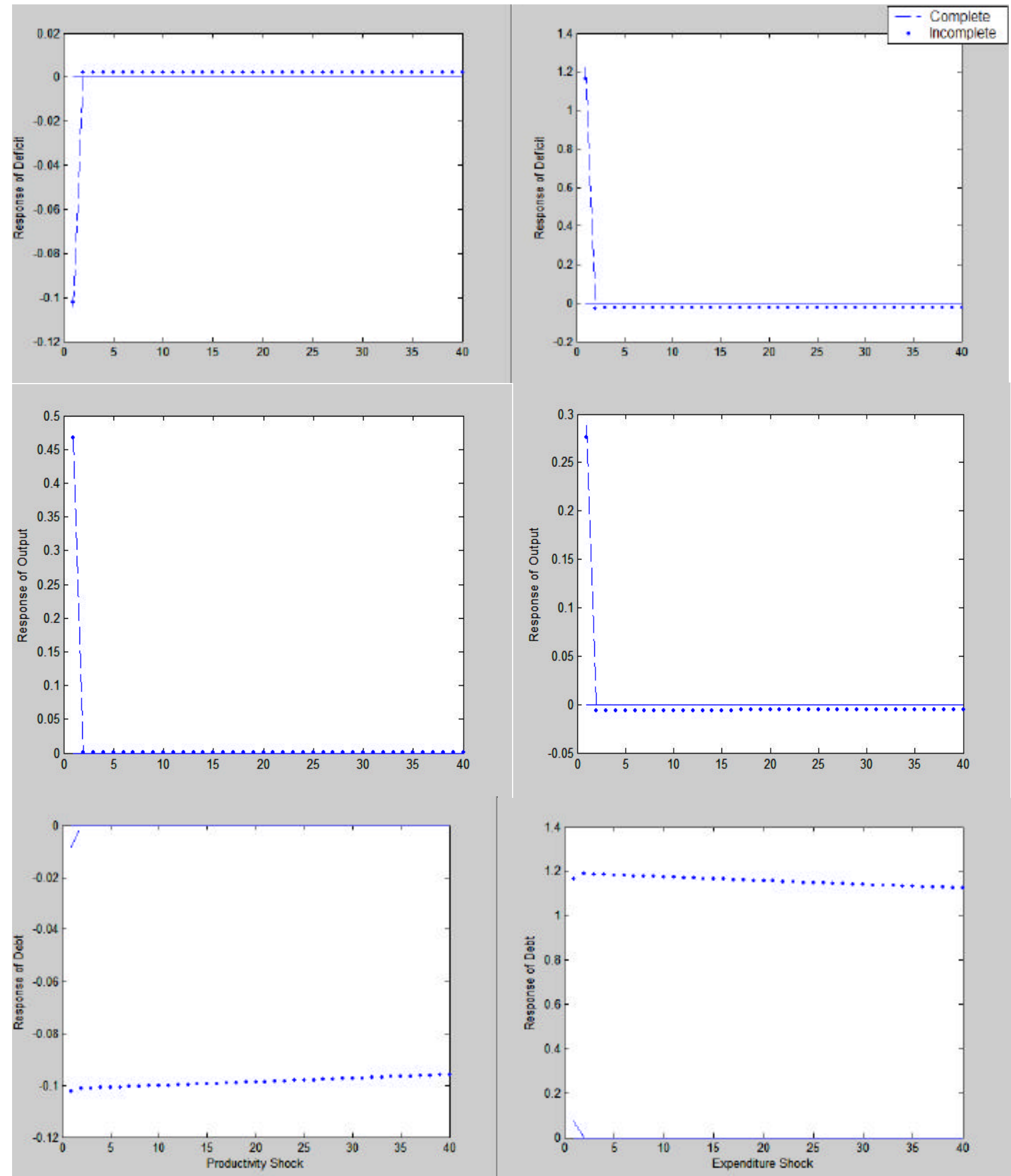

Figure 3

True IRF, Model 1 (iid Shocks) 

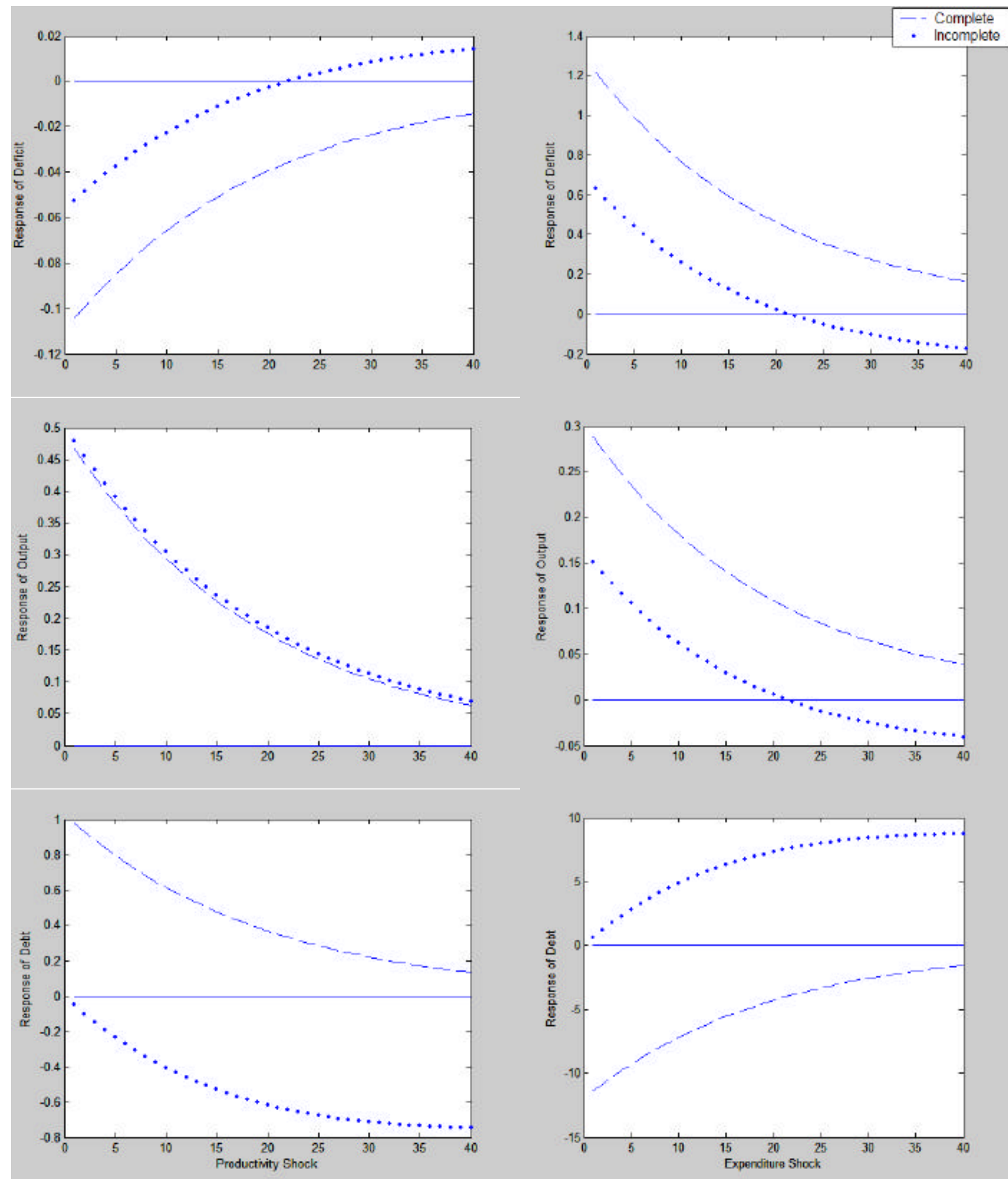

Figure 4

True IRF Model 1 (Persistent Shocks) 

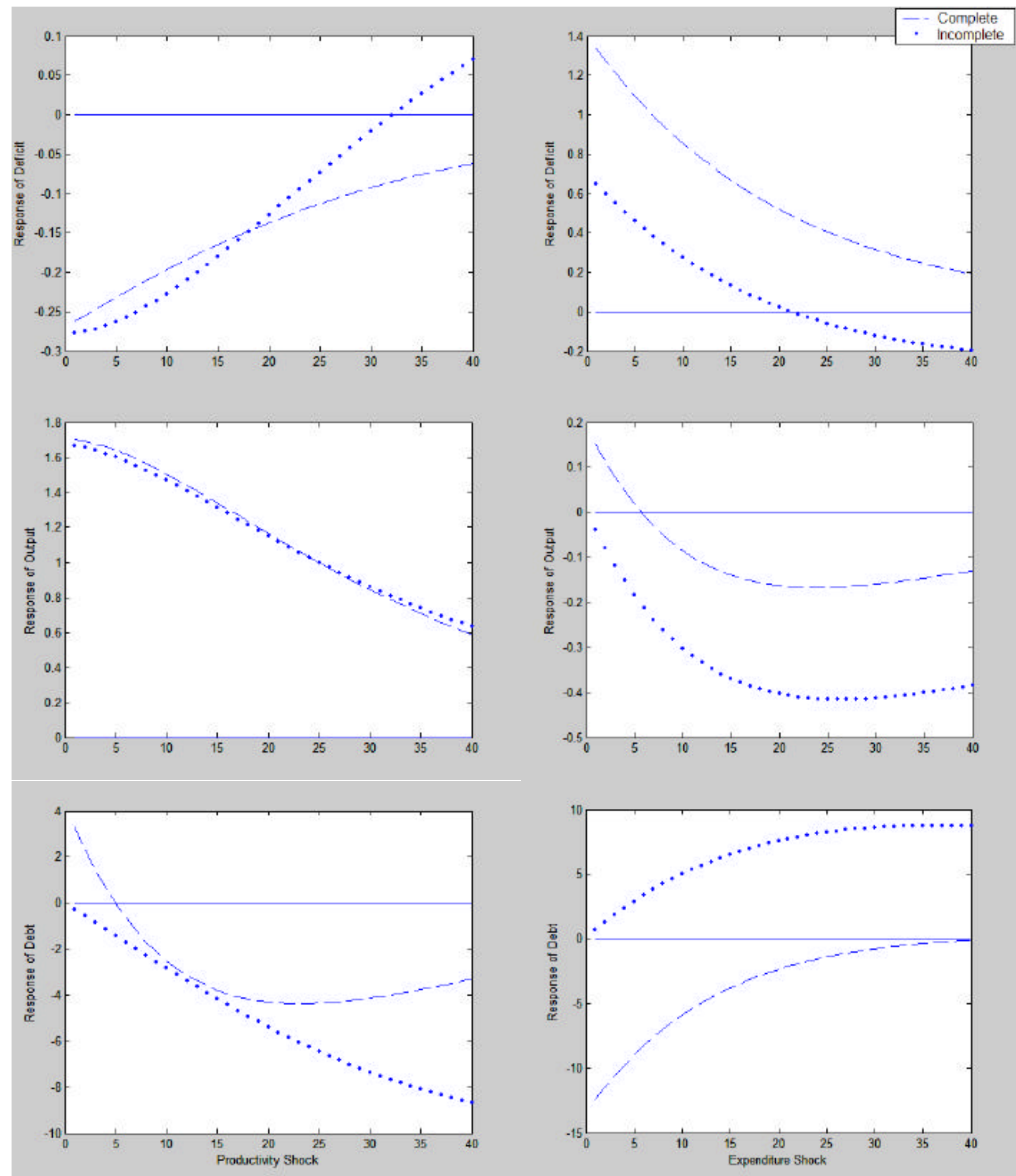

\section{Figure 5}

True IRF, Model 2 (Capital accumulation, persistent Shocks) 

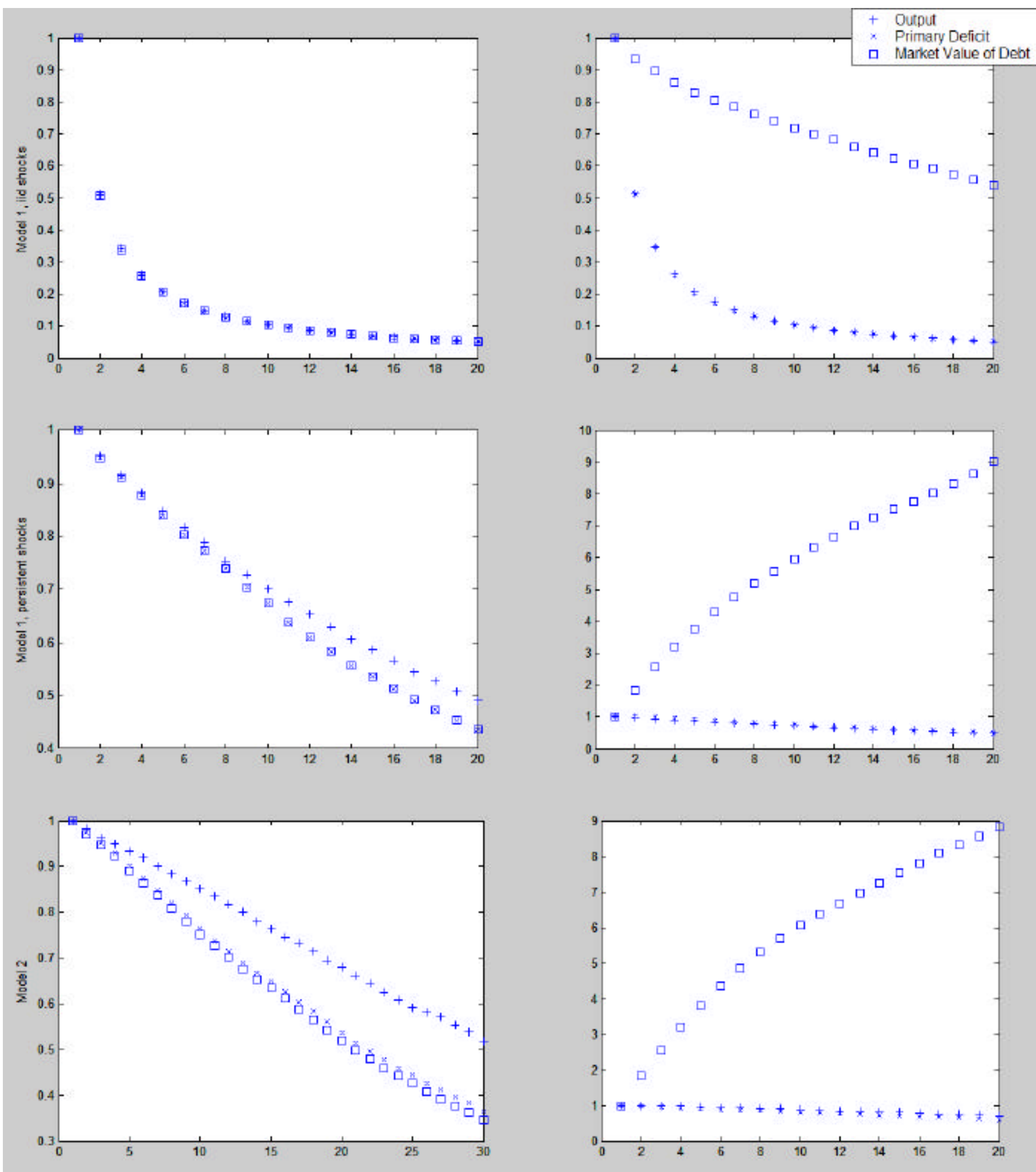

\section{Complete Markets}

Figure 6

k-variance ratios (persistence measures) for all models 
Response to One S.D. Innovations \pm 2 S.E.

Response of LDEFRATIO to LDEFRATIO

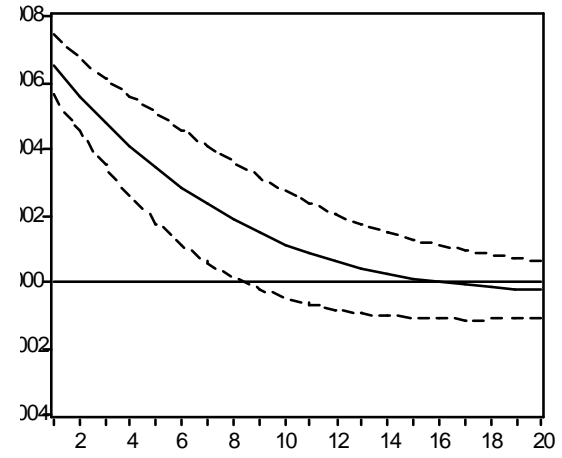

Response of DLGDP to LDEFRATIO

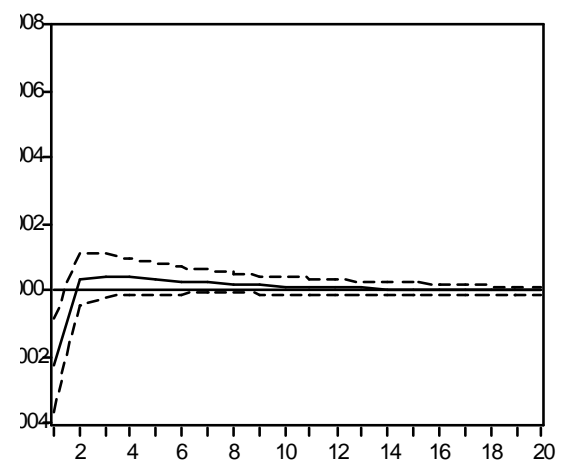

Response of LDEBTRATIO to LDEFRATIO

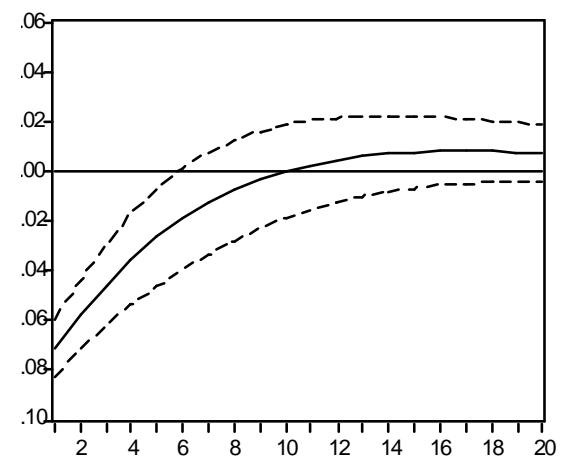

Response of LDEFRATIO to DLGDP

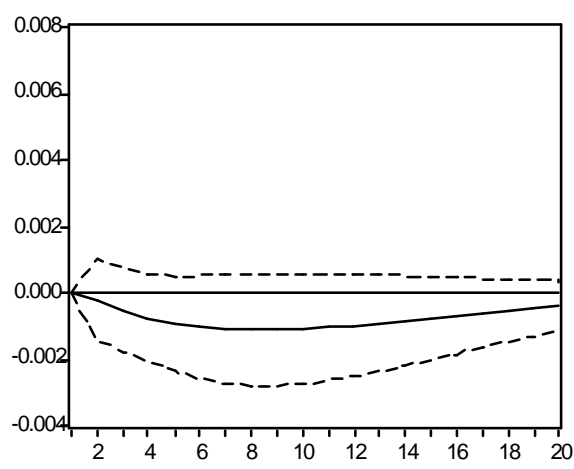

Response of DLGDP to DLGDP

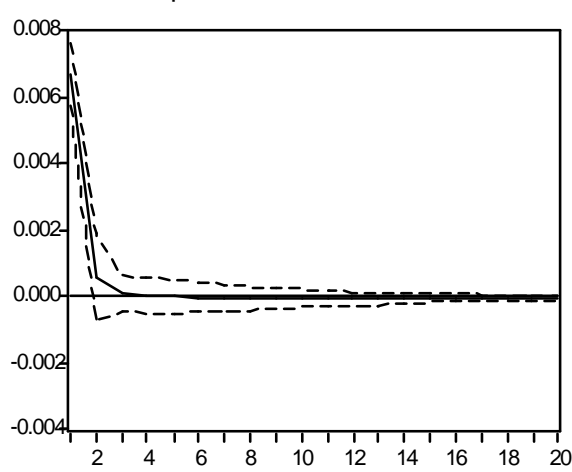

Response of LDEBTRATIO to DLGDP

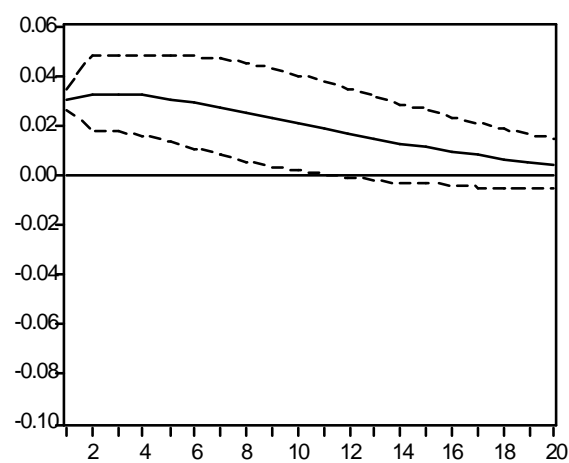

Response of LDEFRATIO to LDEBTRATIO

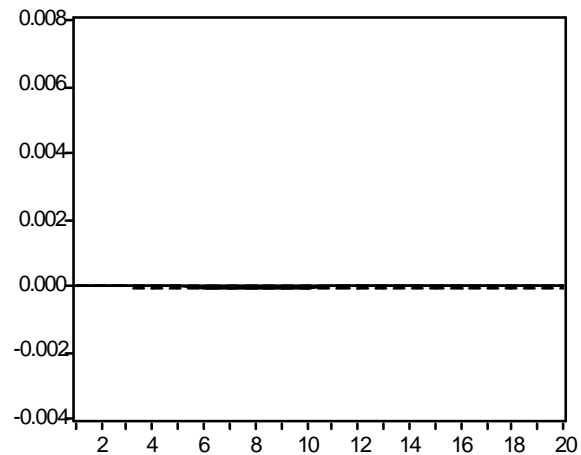

Response of DLGDP to LDEBTRATIO

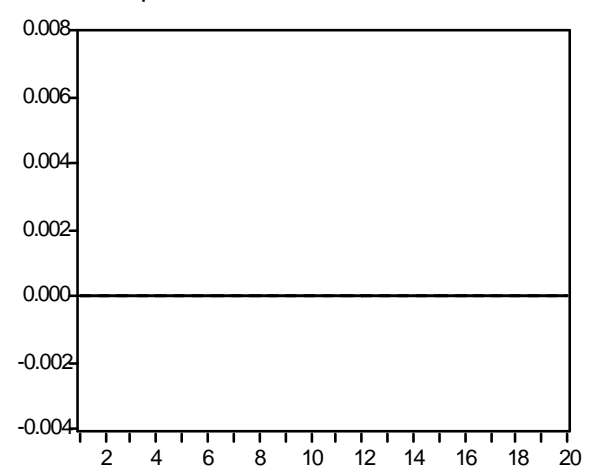

Response of LDEBTRATIO to LDEBTRATIO

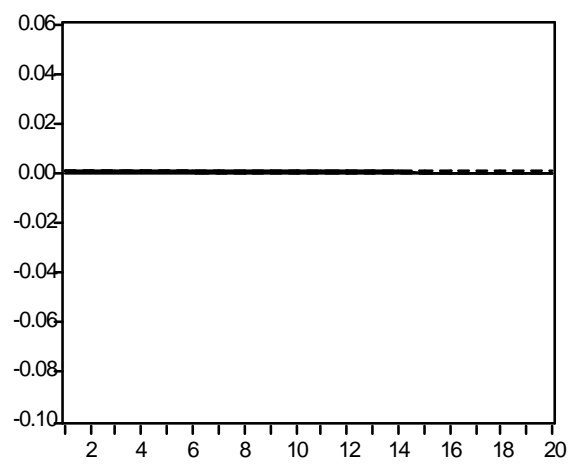

Figure 7

Estimated IRF, Model 2, Persistent Shocks, Complete Markets. 
Response to One S.D. Innovations \pm 2 S.E.

Response of LDEFRATIO to LDEFRATIO

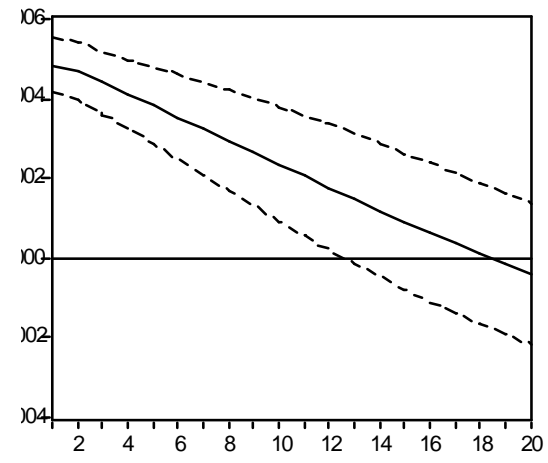

Response of DLGDP to LDEFRATIO

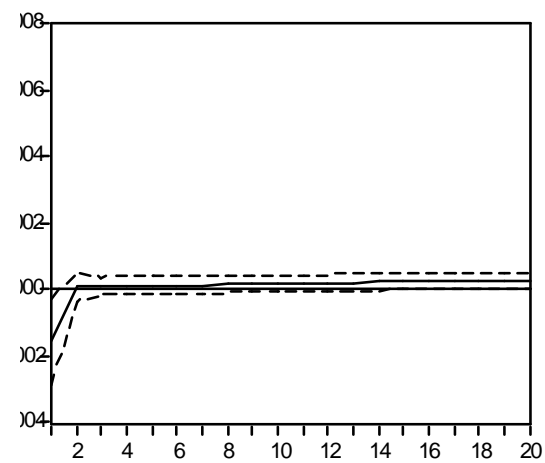

Response of LDEBTRATIO to LDEFRATIO

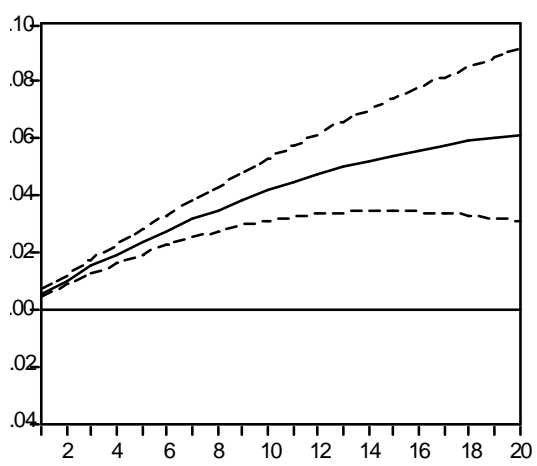

Response of LDEFRATIO to DLGDP

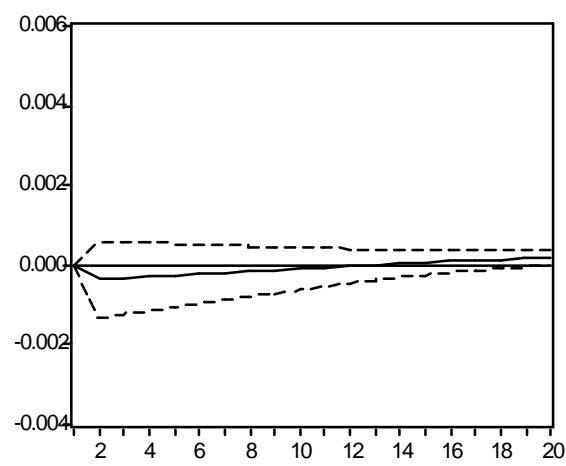

Response of DLGDP to DLGDP

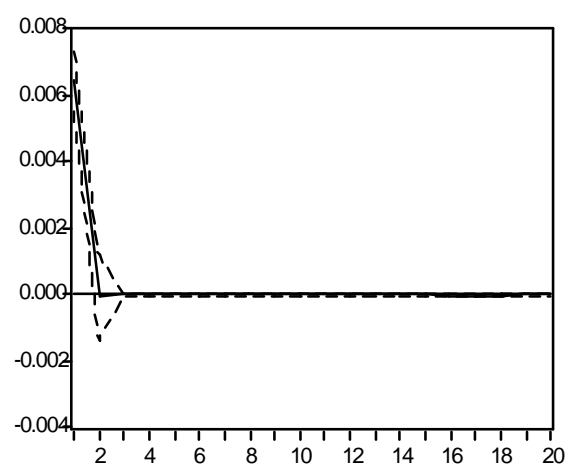

Response of LDEBTRATIO to DLGDP

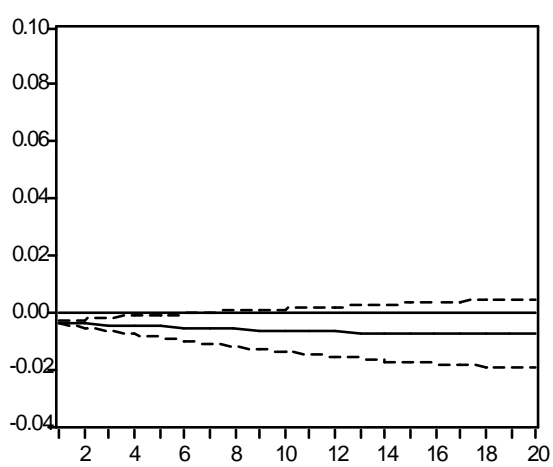

Response of LDEFRATIO to LDEBTRATIO

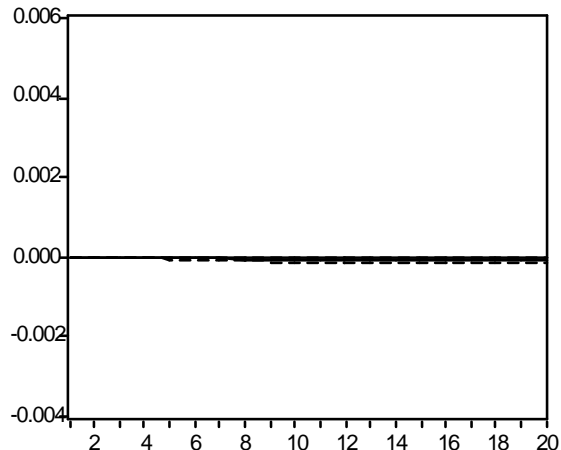

Response of DLGDP to LDEBTRATIO

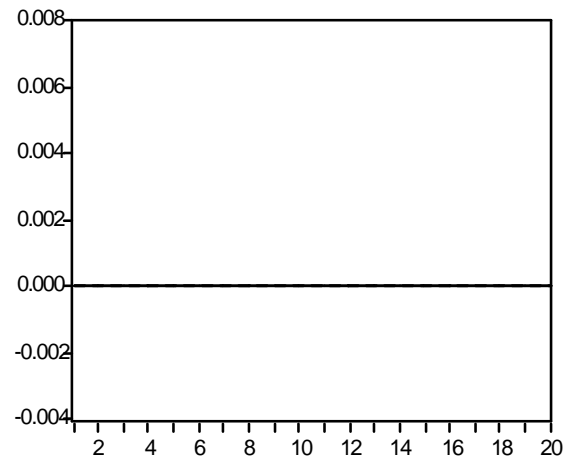

Response of LDEBTRATIO to LDEBTRATIO

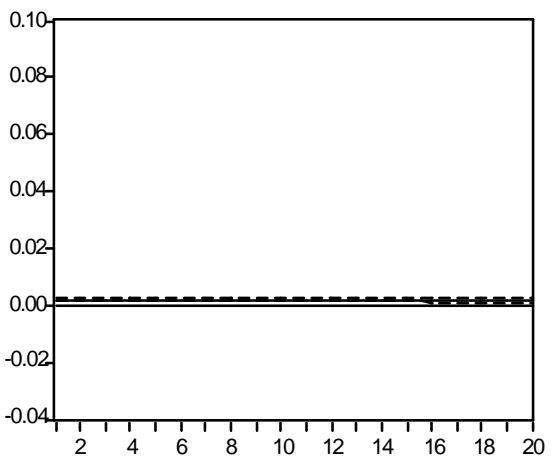

Figure 8

Estimated IRF, Model 2, Persistent Shocks, Incomplete Markets 


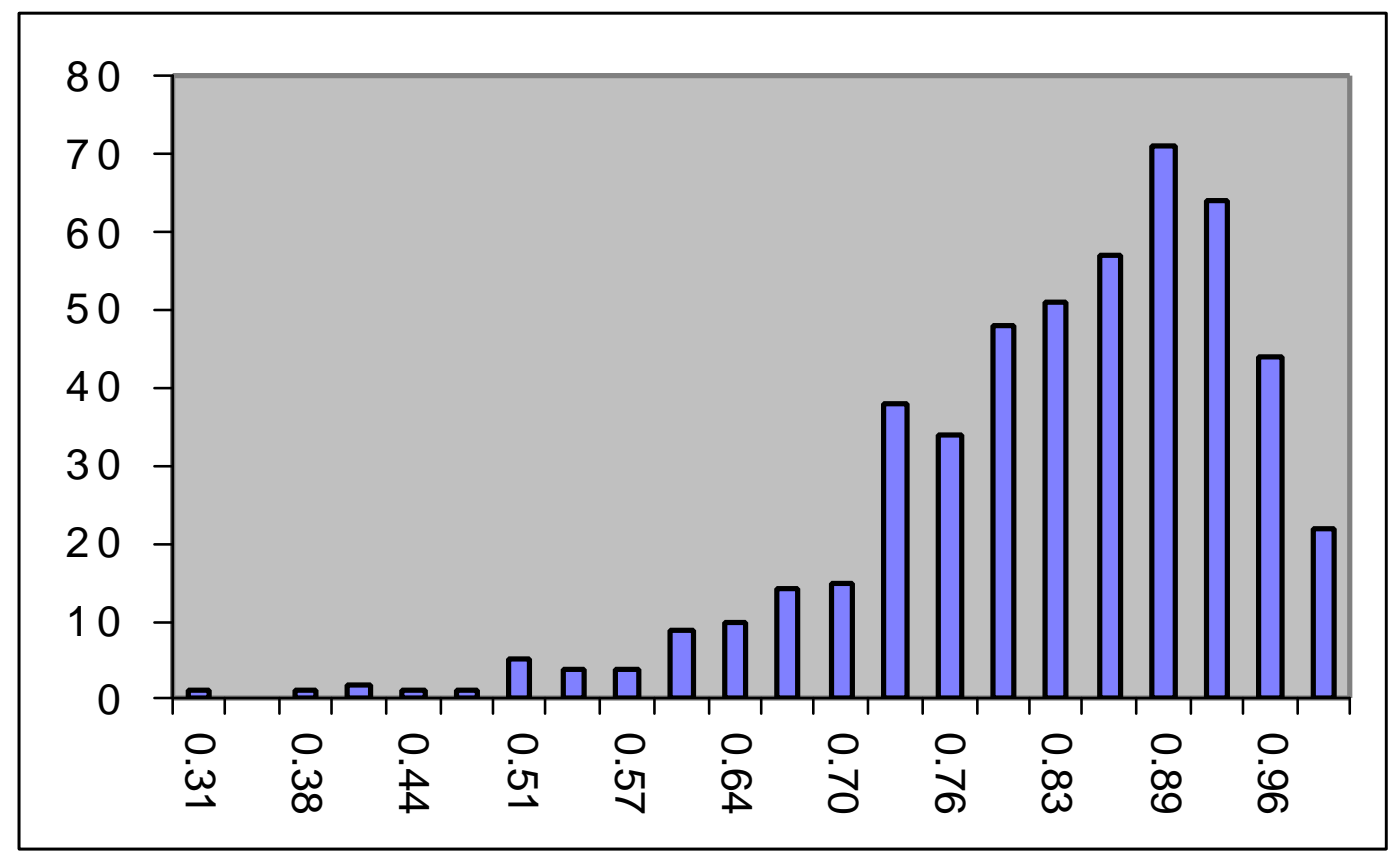

Complete Markets

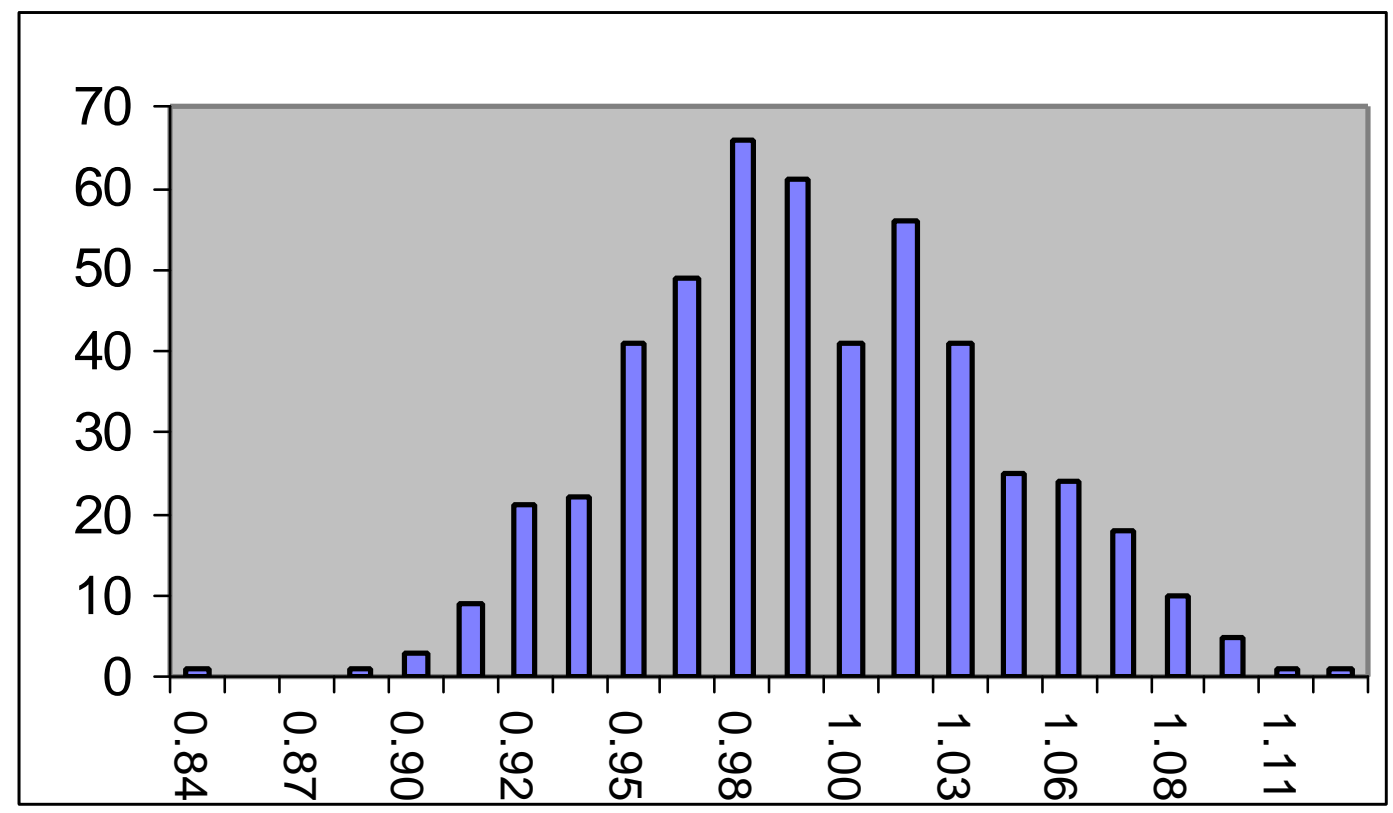

Incomplete Markets

Figure 9

Distribution of OLS estimator of $b$.

Model 1, persistent shocks. Sample $T=40$. 
Table 1

Debt Limit Issues

\begin{tabular}{|c|c|c|c|c|}
\hline & $\begin{array}{l}\text { Min. } \\
\text { Mark. } \\
\text { Value of } \\
\text { Debt }\end{array}$ & $\begin{array}{l}\text { Max. } \\
\text { Mark. } \\
\text { Value } \\
\text { of Debt }\end{array}$ & $\begin{array}{l}\text { \% } \\
\text { Times } \\
\text { Lower } \\
\text { Limit } \\
\text { Binds }\end{array}$ & $\begin{array}{l}\text { \% Times } \\
\text { Upper Limit } \\
\text { Binds }\end{array}$ \\
\hline \multicolumn{5}{|l|}{ Model 1.a } \\
\hline $\begin{array}{l}\text { Complete } \\
\text { Markets }\end{array}$ & -1.4 & -0.5 & - & - \\
\hline $\begin{array}{l}\text { Incomplete } \\
\text { Markets - Tight } \\
\text { Limits }\end{array}$ & -14.7 & 13.3 & 0.7 & 0.1 \\
\hline $\begin{array}{l}\text { Incomplete } \\
\text { Markets - } \\
\text { Moderate Limits }\end{array}$ & -25.7 & 20.1 & 0 & 0 \\
\hline \multicolumn{5}{|l|}{ Model $1 . b$} \\
\hline $\begin{array}{l}\text { Complete } \\
\text { Markets }\end{array}$ & -59.3 & 74.6 & - & - \\
\hline $\begin{array}{l}\text { Incomplete } \\
\text { Markets (Tight } \\
\text { Limits) }\end{array}$ & -13.6 & 13.4 & 14.1 & 2.2 \\
\hline $\begin{array}{l}\text { Incomplete } \\
\text { Markets } \\
\text { (Moderate } \\
\text { Limits) }\end{array}$ & -36.0 & 40.0 & 0 & 0.3 \\
\hline \multicolumn{5}{|l|}{ Model 2} \\
\hline $\begin{array}{l}\text { Complete } \\
\text { Markets }\end{array}$ & -141.8 & 151.8 & - & - \\
\hline $\begin{array}{l}\text { Incomplete } \\
\text { Markets } \\
\text { (Moderate } \\
\text { Limits) }\end{array}$ & -37.9 & 55.1 & 0 & 0.4 \\
\hline
\end{tabular}


Table 2

Debt Management Issues

\begin{tabular}{|c|c|c|c|c|}
\hline \multicolumn{4}{|c|}{ Standard Deviations } & \multirow[b]{2}{*}{$\begin{array}{l}\text { Correlation } \\
\text { Interest } \\
\text { payments } \\
\text { and Primary } \\
\text { Deficit }\end{array}$} \\
\hline & $\begin{array}{l}\text { Primary } \\
\text { Deficit/ } \\
\text { GDP }\end{array}$ & $\begin{array}{l}\text { Total } \\
\text { Deficit/ } \\
\text { GDP }\end{array}$ & $\begin{array}{l}\text { Tax } \\
\text { Rate }\end{array}$ & \\
\hline \multicolumn{5}{|l|}{ Model 1.a } \\
\hline $\begin{array}{l}\text { Complete } \\
\text { Markets }\end{array}$ & 0.018 & 0.017 & 0.002 & -0.837 \\
\hline $\begin{array}{l}\text { Incomplete } \\
\text { Markets }\end{array}$ & 0.017 & 0.017 & 0.006 & -0.139 \\
\hline \multicolumn{5}{|l|}{ Model 1.b } \\
\hline $\begin{array}{l}\text { Complete } \\
\text { Markets }\end{array}$ & 0.046 & 0.029 & 0.006 & -0.992 \\
\hline $\begin{array}{l}\text { Incomplete } \\
\text { Markets }\end{array}$ & 0.020 & 0.017 & 0.052 & -0.574 \\
\hline Model 2 & & & & \\
\hline $\begin{array}{l}\text { Complete } \\
\text { Markets }\end{array}$ & 0.047 & 0.040 & 0.005 & -0.593 \\
\hline $\begin{array}{l}\text { Incomplete } \\
\text { Markets }\end{array}$ & 0.026 & 0.023 & 0.083 & -0.380 \\
\hline
\end{tabular}

